

Review Paper

\title{
A review on the recycling of waste carbon fibre/glass fibre-reinforced composites: fibre recovery, properties and life-cycle analysis
}

\author{
Sankar Karuppannan Gopalraj ${ }^{1}$ (D) Timo Kärki $^{1}$
}

Received: 21 November 2019 / Accepted: 5 February 2020 / Published online: 18 February 2020

(C) The Author(s) 2020 OPEN

\begin{abstract}
The growing use of carbon and glass fibres has increased awareness about their waste disposal methods. Tonnes of composite waste containing valuable carbon fibres and glass fibres have been cumulating every year from various applications. These composite wastes must be cost-effectively recycled without causing negative environmental impact. This review article presents an overview of the existing methods to recycle the cumulating composite wastes containing carbon fibre and glass fibre, with emphasis on fibre recovery and understanding their retained properties. Carbon and glass fibres are assessed via focused topics, each related to a specific treatment method: mechanical recycling; thermal recycling, including fluidised bed and pyrolysis; chemical recycling and solvolysis using critical conditions. Additionally, a brief analysis of their environmental and economic aspects are discussed, prioritising the methods based on sustainable values. Finally, research gaps are identified to highlight the factors of circular economy and its significant role in closing the life-cycle loop of these valuable fibres into re-manufactured composites.
\end{abstract}

Keywords End-of-life · Carbon fibre · Glass fibre · Recycling technologies · Life-cycle loop · Circular economy

\section{Introduction}

The materials commonly used in well-established sectors-such as aircraft, energy, sports, infrastructure, medical, defence, electronics, and automobile are fibrereinforced polymer composites (FRPC) [1-3]. Especially carbon fibre reinforced polymers (CFRP) [4] and glass fibre reinforced polymers (GFRP) [5] are incredibly applicable due to their outstanding material properties $[6,7]$. So far, industries have been rapidly utilising these materials without proper awareness about their disposal methods. For decades, landfill and incineration were the two popular disposal methods adopted by composite industries. These methods have led to increasing environmental awareness to identify a sustainable dispose method and provide a solution to prevent the cumulating wastes [8-14].
In recent decades, various studies have assessed market requirements for new composites and the amount of cumulating wastes to avoid the inevitable negative consequences. By 2020, The US market for fibre-reinforced composites (FRC) will reach an estimated value of $\$ 12$ billion, with an annual growth rate of $6.6 \%$ [15]. Similarly, by the same year, the annual global demand for carbon fibres (CF) is expected to increase from 72,000 tonnes to 140,000 tonnes, and the CFRP global revenue expected to increase from $\$ 28.2$ billion to $\$ 48.7$ billion [16]. To keep up with such a drastic demand for virgin carbon fibre (VCF), the cumulating CFRP waste should be recycled efficiently to reduce environmental impacts and satisfy the need [17]. Indeed, recycling CFRP into a valuable resource is a challenging issue affecting the future of the fibre-based recycling industry [18].

Sankar Karuppannan Gopalraj, sankar.karuppannan@lut.fi | ${ }^{1}$ Fibre Composite Laboratory, LUT University, P.O. Box 20,

53850 Lappeenranta, Finland. 
The cumulating composite wastes are more prominent than the needed new composites. A staggering 62,000 tonnes of unused end-of-life (EoL) and CFRP production waste will be cumulating every year in spite of the existing demand for new fibre composite [16]. The aircraft [19] and wind energy [20] sectors contribute to a major share of this. In the aircraft sector, an estimated value of 23,360 t/y of EoL CFRP will be accumulated if left unrecycled by 2035 . Also, due to developments in modern aviation, the cumulative amounts from the following world regions are estimated to be available for recycling by 2050: North America $(162,083 \mathrm{t})$, Europe $(144,724 \mathrm{t})$ and Asia $(102,500 \mathrm{t})[19]$. Similarly, the EoL wind turbines will be cumulating 483,000 tonnes of CFRP waste, consisting of North America $(95,000 \mathrm{t})$, Europe $(190,000 \mathrm{t})$ and Asia $(146,000 \mathrm{t})$ by 2050 [20]. Additionally, by the same year, wind energy will be replacing traditional electricity production and will account for $50 \%$ of the EU's total electricity consumption [21]. However, despite their green credentials, wind turbine blades made from GFRP have a lifespan of approximately 20 years. This means that, by 2030, an estimated 100,000 tonnes/year of wind turbine blades will be cumulated. Plus, currently, only a few recycling techniques are available to treat such an enormous quantity $[21,22]$. After wind turbines, waste printed circuit boards (WPCBs) represents one of the fastest-growing global waste streams [23], contributing a significant share to overall electronic waste and consisting of 27.4-45.55 wt\% glass fibres (GF) [24,25]. Recycling WPCBs to recover GFs is a challenging process due to the presence of toxic heavy metals and organic compounds, along with the GFs themselves [26].

Current landfilling percentages recorded in the UK stand at $35 \%$ for CF and $67 \%$ for GF, with only $20 \%$ of CF and $13 \%$ of GF recycled and a small amount $2 \%$ CF and $6 \%$ GF-being reused [27]. Furthermore, $2000 \mathrm{t} / \mathrm{y}$ of CF waste ( $20 \%$ of the total CF made in the US), if rescued from landfills and properly recycled, can be worth up to $€ 14.7$ million of recycled carbon fibre ( $\mathrm{rCF}$ ) considering $€ 10 / \mathrm{Kg}$ as the $\mathrm{rCF}$ market price. This value can increase dramatically to over $€ 50$ million by 2020 , arguably due to a stable $15 \%$ annual increase in vCF production worldwide [28]. To develop new markets, an economically sustainable recycling model for CFRP and GFRP waste should be utilised $[27,29,30]$, opening up both direct and indirect job opportunities and contributing to economic development [31].

In the current situation, a complete recovery of fibres (direct structural recycling approach) is considered to benefit the composite sector. The recycled fibres from this approach have an added market value because of the low usage of natural resources, energy, and labour-power, together with near-virgin fibre quality [1]. Numerous methods, especially mechanical, thermal and chemical-based recycling approaches, have been studied and established so far because method selection depends on the type of material to be recycled and the application in which it will be reused [2]. Also, identifying one standard recycling method among various methods is difficult.

In the research field, recycling CFRP and GFRP waste have progressively become an area of interest, as shown when assessing the overall literature studies of the past 20 years-highlighted in Fig. 1. There has been a steady growth in the recycling of both types of fibres. However, after 2011, studies related to CF recycling show an exponential growth without any deviation. Indeed, focusing on review articles, in particular, shows that previous studies have concentrated on either CF or GF or their Life-cycle analysis. But not all three factors combined into a single study. For the present scenario, such review articles are needed to compare various phenomena and to identify research gaps.

The method adopted in this study is a standard narrative review structure proposed by Green et al. [32]. The challenging literature search was conducted primarily in the Scopus database, and three additional databases were used as secondary supporting platforms such as Web of Science, Science Direct and Research Gate. The search was limited to the last 20 years. During the search, keywords such as "carbon fibre", "glass fibre", "Kevlar", "Twaron", "waste carbon fibre", "waste glass fibre", "waste Kevlar", "waste Twaron", "recycling", "recycle", and "recycled" were used. In the end, relevant articles were carefully selected based on an analysis of the title, aim, and novel findings from the research. Considering the limited information available on the topic of recycling Kevlar and Twaron waste, both the fibres were eliminated from this study.

However, all the relevant articles under the recycling of CF waste ( 360 articles) and GF waste ( 85 articles) were reviewed and organised into a private database using Microsoft Excel. A further article selection was made based on the following criteria: a focus on recycling methods; the mechanical properties of recycled

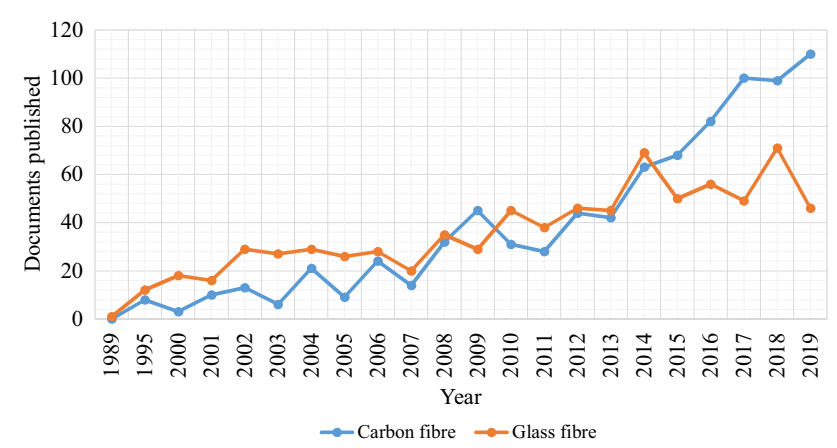

Fig. 1 Number of articles published based on CF and GF recycling for the past 20 years 
fibre; and the economic and environmental analysis of the recycling methods. Articles that deviated from the framed selection criteria were eliminated. Overall, this literature review is narrowed solely focusing on summarising the significant techniques to recycle CF and GF waste. Based on the effective recycling circumstances to recover clean fibres, on the characteristics of the recovered fibres, on the life-cycle analysis of the recycling process. Finally, 153 articles were used in the reference list.

Overall, this review article will provide insights into the current status of recycling methods available to recover both the carbon fibre and glass fibre from their composite wastes. The study will also prioritise the available recycling methods based on the following factorssuch as environmental impact, commercial value, quality of the recovered fibre and recyclability on an industrial scale. Additionally, the study highlights the process conditions associated and the characteristics of the resulting fibres to justify the necessity to replace virgin fibres with recycled fibres.

This paper is organised based on the available recycling methods in three sections, as shown in Fig. 2. The traditionally used mechanical recycling techniques and their latest alternative approaches are presented in Sect. 2. Thermal recycling techniques, including the fluidised bed process and pyrolysis process, are presented in Sect. 3. The chemical recycling techniques and their latest alternative approaches, along with solvolysis, are discussed in Sect. 4. Subsequently, Life-cycle analysis comparing all the significant factors are discussed in
Sect. 5. After a brief discussion in Sect. 6, the paper ends with the conclusions in Sect. 7.

\section{Mechanical recycling}

In general, mechanical recycling is a technique used to reduce the size of scrap composites into smaller pieces known as recyclates. Normally, slow-speed cutting or crushing mills are used to reduce the material size to 50-100 mm but, when the scrap composites are homogeneous without any metal components, high-speed milling will be adapted to reduce the size between $50 \mu \mathrm{m}$ and $10 \mathrm{~mm}$ [33]. The recyclates are classified based on coarse recyclates (higher fibre content) and fine recyclates (higher resin content) using cyclones and sieves. The effective reusing of recyclates is based on particle size [33, 34]. In the current situation, this has been used as a pre-recycling process for various methods $[35,36]$.

Even though the mechanical recycling process is capable of recycling both CFRP and GFRP, most of the research focuses on GFRP $[2,33,37]$. Discontinuous recyclates and their re-incorporation with low-value applications like fillers or reinforcements can provide the main reasons for such research variation [4]. Besides, CFs are expensive compared to GF. Disrupting their physical integrity by mechanical recycling can lead to economic and fibre property loss. Since the early development of the process, serious drawbacks have been involved, even though studies like Mou et al. [38] showed the improved flexural strength of concrete after the addition of GF recyclates as
Fig. 2 The adopted recycling methods

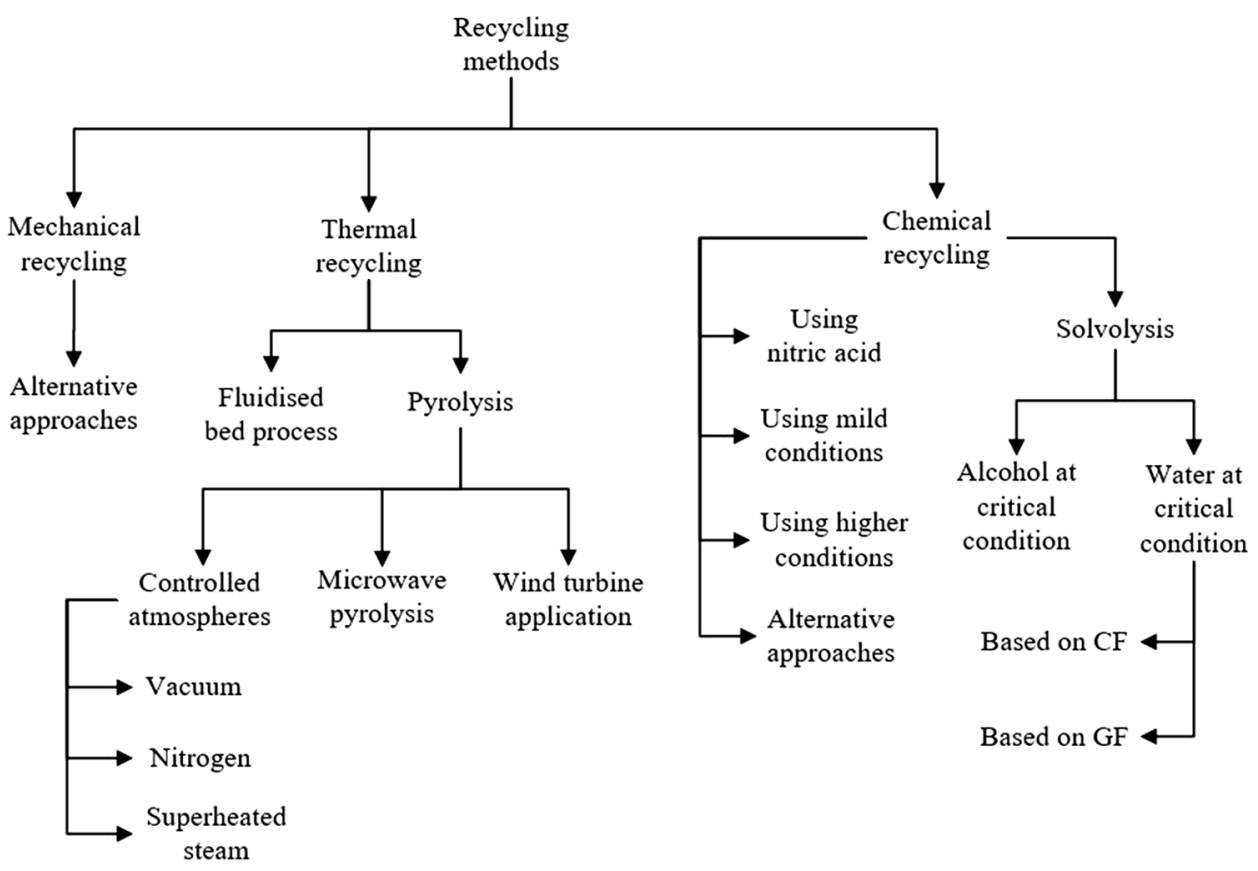


filler materials. Studies like Pickering [33], however, noted that the GF recyclates used as fillers are not commercially feasible due to the availability of alternative cheap virgin fillers such as calcium carbonate or silica.

To overcome the limitations, recent studies show acceptable improvements in the process; for example, studies like Meira Castro et al. [39], which used computational intelligence for optimisation. This involved waste GFRP recyclates being used as aggregate and filler replacement in a concrete-polymer composite to showcase improvements in compressive and flexural strength. Moreover, this optimised process was cost-effective when compared to the thermal and chemical recycling process. Also, Shuaib and Mativenta [40] improved both the yield and quality of the GF recyclate by using low energy consumption. Their study found that reducing the screen size to obtain a fine recyclate will result in increased energy consumption and processing time. To overcome such energy loss, the clearance gap between blades and screen was decreased. In comparison, further increasing the yield without any residue, Kočevar and Kržan [41] separated $70 \%$ of the GF using a normal hammer mill. The remaining $30 \%$ of waste was used as filler material for thermoplastics.

As mentioned previously, the limitations of recycling CFRP waste were challenging and even visible in the latest study by Li and Englund [42], where aerospace industry scrap was size-reduced using a hammer mill followed by shredding. The recyclates are compression moulded into flat pallets and subjected to mechanical testing, which showed a minimum $50-60 \%$ decrease in mechanical properties compared to the original composite. However, the study pointed out that, as the CF recyclate particle size decreases, the mechanical property increases.

\subsection{Alternative approaches}

Recent studies have focused on alternative size-reduction approaches using high voltages. One such method was electrodynamical fragmentation (EDF) in which a high voltage pulse between 50 and $200 \mathrm{kV}$ was passed into ionised water to break down the CFRP waste into smaller pieces $[43,44]$. Similarly, high voltage fragmentation (HVF) was carried out using a high voltage pulse of $160 \mathrm{kV}$ to breakdown the GFRP waste. This method produces clean and long fibres. Moreover, HVF can be a promising alternative to mechanical recycling [45]. However, recently, Oshima et al. [46] pointed out two drawbacks in this approach, using high voltage to remove resin from CFRP waste will result in a severe weight loss in the actual composite and also decreases the rate of resin removal.

\section{Thermal recycling}

In a thermal recycling process, heat is used to break down the scrap composite. Due to a higher operating temperature $\left(450-700^{\circ} \mathrm{C}\right)$, the insignificant volatile materials are likely burnt, leaving the valuable fibres behind. Usually, the process temperature depends on the type of resin utilised in the scrap composite. Improper temperature can either leave char on the fibre surface (undercooked) or result in reducing the diameter of the recovered fibres (overcooked) $[2,47]$. Thermal recycling can be classified into three types [33], as shown in Fig. 3.

The basic principle for decomposing the scrap composite using heat remains the same, though, the results are different for each process. Since polymeric compounds have certain calorific values, electricity can be produced by converting the waste composite into heat [1, 2]. However, a major drawback in the combustion (incineration) process is the ash by-product, which can only be landfilled as inert waste, e.g. $92 € /$ tonne in France. This complication harms the progress of a circular economy. Besides, it is only possible to achieve a $35 \%$ efficiency rate when converting the heat to electricity. Overall, coal in the furnace is a much better option than incinerating CFRP. Recent studies have focused on complete fibre recovery using thermal recycling processes like fluidised-bed process (FBP) and pyrolysis [48].

However, instead of completely combusting CFRP, controlled resin decomposition at optimum temperature can result in CF recovery with negligible surface damage. In a study by Matielli Rodrigues et al. [47], the versatile compounds (resins) were thermally disintegrated at $450^{\circ} \mathrm{C}$ for $2 \mathrm{~h}$ and $\mathrm{CF}$ recycled without damaging much of the surface integrity. The decomposed epoxy resins are derived from the diglycidyl ether of bisphenol-A (DGEBA), which is difficult to recycle due to its cross-linked structure from resin curing. Therefore, recycling with minor surface damage is a better option than landfilling completely.

Resin decomposing using optimal thermal conditions is not as efficient for GF as $\mathrm{CF}$, but post-chemical treatments of recycled glass fibre ( $\mathrm{rGF}$ ) help to a certain extent in regaining their properties [49]. Unlike CF, the thermal recycling of GF in high-heat operating conditions $\left(300-600^{\circ} \mathrm{C}\right.$ )

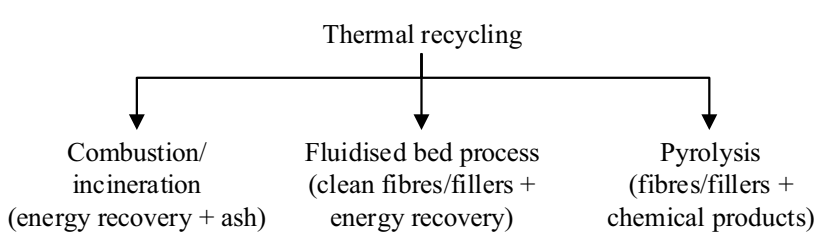

Fig. 3 Classification of thermal recycling 
reduces the strength of the resulting GF up to $80 \%$ and is difficult to further reuse because of its low reinforcement potential [50,51]. To overcome such phenomena, Yang et al. [50] investigated two chemical treatments: chemical etching and post-silanisation to treat decomposed GF ( $80 \%$ decreased tensile strength) at $500{ }^{\circ} \mathrm{C}$ for $30 \mathrm{~min}$. The post-chemical treatment retained $30-70 \%$ of the lost mechanical properties in rGF. Thomason et al. [49] recovered $75 \%$ of the strength-loss by immersing the GF in $3 \mathrm{M} \mathrm{NaOH}$ solution for $10 \mathrm{~min}$ at $90^{\circ} \mathrm{C}$, followed by neutralising with $\mathrm{HLC}$. The treatment is known as short-hot sodium hydroxide solution treatment. Pender and Yang [52] introduced catalysts: $\mathrm{CuO}, \mathrm{CeO}_{2}$, and $\mathrm{Co}_{3} \mathrm{O}_{4}$ to boost the resin decomposition. As a result, the processing time was reduced by $20 \mathrm{~min}$, along with a $40 \%$ reduction in energy consumption. Among the three catalyses, $\mathrm{CuO}$ at $375^{\circ} \mathrm{C}$ had maximum efficiency in removing the resins, while $\mathrm{CuO}$ and $\mathrm{CeO}_{2}$ increase $20 \%$ of GF's strength retention capacity.

\subsection{Fluidised bed process}

In a typical fluidised bed process (FBP), a rapid stream of hot air is passed through a bed of silica sand to decompose the chopped scrap composite at a low temperature. Usually, a fine silica sand of $0.85 \mathrm{~mm}$ particle size is used as a bed, which is then converted into a fluidised bed by passing air in the velocity range $0.4-1.0 \mathrm{~m} / \mathrm{s}$. The polymeric matrix scrap composites are chopped to $25 \mathrm{~mm}$ and fed separately into the fluidised bed. The operating temperature is between 450 and $550^{\circ} \mathrm{C}$. Inside a fluidised bed, the scrap composite separates into fibres and fillers (volatile compounds), which are carried out by the air stream as individual particles $[33,53]$.

Furthermore, suspending the individual particles in a high-temperature $\left(1000^{\circ} \mathrm{C}\right)$ secondary chamber will result in oxidising the volatile compounds, leaving the fibres alone $[33,53]$. Figure 4 represents a diagram of the FBP. The process is capable of recovering both CF and GF [33] and is especially favourable for recycling EoL waste composites [2]. However, during the initial development of the process, limitations like fibre strength and length degradation became apparent. Also, the recovered fibres are fluffy [4].
The limitations are noticeable in Pickering et al. [53], as their research investigated the ability of FBP to recycle GF and was only able to achieve a $67 \%$ fibre yield. Furthermore, the process retained only $50 \%$ of the tensile strength of the rGF compared to virgin GF (vGF). However, the study included a cost analysis for commercialising the process and estimated that for 9000 tonnes/ year, the net annual profit would be $0.002 \$$ million/year. Besides the limitations, the author's contribution to the process has laid the foundations for modern-day FBP [4]. In contrast with Pickering et al. [53] results, Zheng et al. [55] claimed to have a novel FBP approach to recycle WPCBs, achieving a $94.8 \mathrm{wt} \%$ GF recovery rate and a $95.4 \mathrm{wt} \%$ purity rate. The recycling approach seems to be almost similar, except for the WPCB were finely chopped than regular chopping size $(25 \mathrm{~mm})$ before feeding. However, the results were validated based on weight loss and SEM micrographic image observations. Plus, no information regarding the strength of the rGF's was mentioned. To improve the yield of rGF, Pender and Yang [56] used CuO as a catalyst, with the results improving the yield from 59 to $70 \%$.

A similar study to Pickering et al. [53] but replacing GF with CF was carried out by Yip et al. [57]. The findings showed that recycling CF by using identical operating conditions was much more efficient compared to GF recycling. The rCF had fully retained Young's modulus and $75 \%$ of tensile strength when compared to vCF. The study also mentioned that the rCF length depends on the initial length of the CF waste, and it was possible to recover a fibre length of 5.9-9.5 $\mathrm{mm}$ despite the nonuniform orientation. In alignment with previous studies, Pickering et al. [54] systematised the idea of commercialscale FBP with its ability to recover CF and also designed a commercial scale FBP suitable for recycling mixed and contaminated CFRP waste. The rCF only had an $18.2 \%$ tensile strength decrease and no tensile modulus reduction. The study claimed that the design has the highest efficiency compared with any other rCF using FBP. Also, the energy consumption to recover $C F$ via FBP is only $5-10 \%$ of the total energy needed to manufacture vCF.
Fig. 4 Fluidised bed process (modified from Pickering et al. $[53,54])$

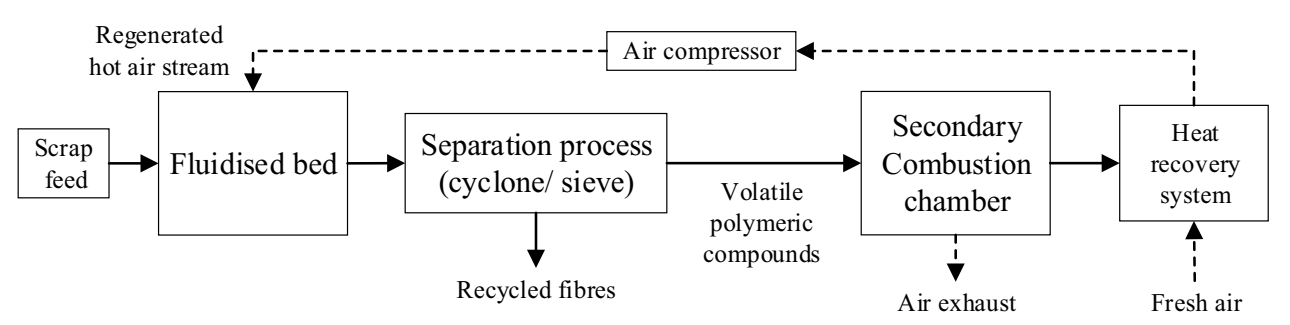

SN Applied Sciences A SPRINGER NATURE journal. 


\subsection{Pyrolysis process}

The process is efficacious for recycling both CF and GF [15]. Unlike other thermal recycling processes, the scrap composites are heated in the absence of oxygen. Under this condition, the decomposing matrix produces oil and gas, along with fibres and fillers (solid products) $[2,33]$. In a typical polymeric pyrolysis process, the operating temperature varies in the range of $400-700{ }^{\circ} \mathrm{C}$ depending on the nature of the scrap composite $[1,4]$. The liquid produced from the process contains aromatic compounds and has a calorific value of $37 \mathrm{MJ} / \mathrm{Kg}$, similar to fuel. The gas produced can be regenerated into the pyrolysis reactor. Overall, the oil and gas products produced can prove a significant chemical feedstock for any other process. Nevertheless, in spite of all that is produced, the process is still capable of retaining fibres with higher mechanical properties [1, 4]. This clarity of effect makes pyrolysis the most studied thermal recycling process [2], Fig. 5 presents a flowchart of the process.

Like any other recycling process, pyrolysis also suffers from certain limitations, with the possibility of char formation on the resulting fibre surface considered the most challenging of all [4]. A significant percentage decrease in the mechanical properties can be observed in the recovered fibres due to the char. Methods such as chemical treatment $[26,58]$ and post-heating the fibres result in reducing the char formation, but only to a certain extent [1]. Recent studies have used carbon dioxide $\left(\mathrm{CO}_{2}\right)$ and water vapours to remove the char formation from CFRP [59]. Also, oxidising the fibre surface will result in the formation of an oxygen-rich surface, improving the adhesive nature of the fibre with resins [60].

To completely avoid such char formation on the recovered CFs, a UK milled carbon group was successful in designing and implementing a commercial-scale semi-open continuous belt furnace with a controlled atmosphere $[4,61]$. Similarly, Germany's CFK Valley Stade Recycling $\mathrm{GmbH}$ and $\mathrm{Co}$. KG uses a continuous pyrolysis process. Both companies are capable of recycling various types of CFRP waste. Moreover, the large furnace and

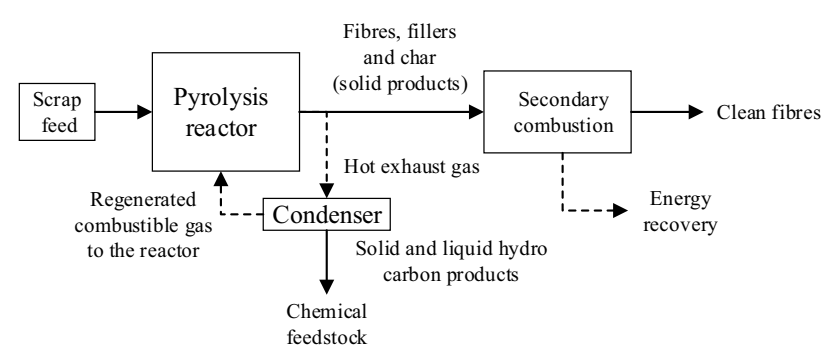

Fig. 5 Pyrolysis process (modified from Pickering et al. [33]) continuous flow allow them to recover longer and cleaner CFs [4]. Evidence for such a phenomenon can be seen in an earlier study from Meyer et al. [62] on recycling aircraft manufacturing CFRP waste, in which low-efficiency labscale pyrolysis was optimised to a semi-industrial scale with the help of the company ReFiber. The authors were able to synthesise semi-industrial plant operations using a larger oven, with rCF retaining $96 \%$ of its original tensile strength. However, a secondary heating system was implemented to eliminate the residue char, though the rCF was effective enough to replace vCF. Overall, a controlled atmosphere in the pyrolytic reactor can influence the process outcomes.

\subsubsection{Pyrolysis: controlled atmospheres}

The development of pyrolysis processes resulted in sophisticated and controlled atmospheric conditions being added to separate fibres from the solid pyrolysis products. Various literature works published since 2010 include evidence of such an approach. The primary principle of pyrolysis is unaffected. However, the atmospheric conditions inside the pyrolytic reactor have changed constantly, aiming for higher yields. Three commonly-used atmospheric conditions during pyrolysis are vacuum, nitrogen and superheated steam.

3.2.1.1 Vacuum atmosphere Inside a vacuum pyrolytic reactor, the organic vapours' residence time is shorter due to a low decomposition temperature, which is sufficient enough to recycle GF without disturbing surface integrity $[63,64]$. In an early study focused on recycling WPCBs by Zhou and Qiu [63], vacuum pyrolysis (VP) was judged as an alternative approach to mechanical recycling. The liquid and gas products (can be used as chemical feedstock) along with solid products (GF and metal components) were found to increase the interests of researchers when compared to mechanical recycling $[24,63,64]$. Their study consists of a two-step pyrolysis method, such as VP and vacuum centrifugal separation (VCS), to separate GF from WPCBs. Similarly, Long et al. [24] used VP, which involved the GF being separated from metal parts using gravity separation (GS) method and non-metal parts using a calcination process. The studies focused on recycling WPCBs using a vacuum atmosphere did not include any investigation on the mechanical properties of rGF. However, the yields from the process are tabulated in Table 1. This process is limited to GF as no suitable study was found concerning $\mathrm{CF}$.

3.2.1.2 Nitrogen atmosphere Unlike vacuum pyrolysis, pyrolysis under a nitrogen gas atmosphere is capable of recycling both CFRP and GFRP [61]. Pyrolysis under 
Table 1 Pyrolysis yields (wt\%) from recycled CFRP and GFRP

\begin{tabular}{|c|c|c|c|c|c|}
\hline References & Material & Solid yield & Liquid yield & Gas yield & Process parameters \\
\hline Zhou and Qiu [63] & GF & 75.7 & 20 & 4.3 & \multirow{2}{*}{$\begin{array}{l}\text { a. VP: } 600^{\circ} \mathrm{C} \text { for } 30 \mathrm{~min} \\
\text { b. VCS: } 400^{\circ} \mathrm{C}, 1200 \mathrm{rpm} \text { for } 6-10 \mathrm{~min}\end{array}$} \\
\hline Zhou et al. [64] & GF & 72.2 & 21.45 & 6.35 & \\
\hline Long et al. [24] & GF & 74.7 & 15 & 10.3 & $\begin{array}{l}\text { a. VP: } 550{ }^{\circ} \mathrm{C} \text { for } 120 \mathrm{~min} \\
\text { b. GS + calcination: } 600^{\circ} \mathrm{C} \text { for } 10 \mathrm{~min}\end{array}$ \\
\hline Onwudili et al. [65] & $\mathrm{CF}$ & 77 & 20.6 & 2.4 & $\begin{array}{l}\mathrm{NA}: 400-500^{\circ} \mathrm{C}<30 \mathrm{~min}+\mathrm{SC}: 450^{\circ} \mathrm{C} \\
\text { for } 2 \mathrm{~h} .\left(35 \mathrm{MJ} \mathrm{m}^{-3} \text { calorific value }\right. \\
\text { of gas) }\end{array}$ \\
\hline \multirow[t]{2}{*}{ Onwudili et al. [61] } & $\mathrm{CF}$ & 73.1 & 23.8 & 2.3 & \multirow{2}{*}{$\begin{array}{l}\text { NA: } 500{ }^{\circ} \mathrm{C} \text { for } 45 \mathrm{~min} \text { with } 5 \mathrm{dm}^{3} / \mathrm{h} \\
\text { nitrogen + SC: } 500^{\circ} \mathrm{C} \text { for } 30 \mathrm{~min} \text { at } \\
20^{\circ} \mathrm{C} \mathrm{m^{-1 }}\end{array}$} \\
\hline & GF & 65.9 & 25.7 & 8.4 & \\
\hline
\end{tabular}

nitrogen atmosphere (NA) was the popular pyrolysis process used to recycle WPCBs until Zhou et al. [64] 's study came in 2010. The study used vacuum pyrolysis to recycle WPCBs, achieving a maximum GF recovery. However, later analysing the advantages of pyrolysis under NA, in 2013, Onwudili et al. [65] further developed the process and successfully recycled CFRP waste-in which 98 wt\% of the solid products ( $\mathrm{rCF}$ ) were recovered efficiently. The study stated that a reaction time increase could cause a decrease in the mechanical properties of the recycled CF. Also, insufficient reaction time could result in char formation on the fibres. The yield from the process is tabulated in Table 1.

In line with previous research, in 2016, Onwudili et al. [61] investigated the mechanical properties of both the recycled CFRP and GFRP waste using a nitrogen atmosphere in a semi-batch reactor. The study found that chemical modification on the surface of recycled CF and GF could improve fibre properties. Additionally, both studies $[61,65]$ used secondary combustion (SC) to oxidise minor resin impurities and char formation on the pyrolysed fibres. When comparing the results, oxidised fibres retained the most mechanical properties when compared to non-oxidised fibres.

3.2.1.3 Superheated steam atmosphere In general, superheated steam is produced as a result of heating saturated steam at constant pressure. During the transition phase, the steam is heated several times above its saturation point to achieve superheated levels. The use of superheated steam atmosphere in pyrolysis increases heat transfer, which results in heightening the thermal degradation and supporting an oxygen-free atmosphere inside the pyrolytic reactor [66]. Recycling CFRP using superheated steam results in a high retaining of the CF mechanical properties when compared to any other pyrolysis atmospheres $[67,68]$. Also, a significant amount of the char formation on the resulting CF and GF can be reduced using chemical treatments [58].

Using pyrolysis under superheated steam, Shi et al. [67] investigated the mechanical properties of rCF. They found that the recycled fibres had a substantial amount of char on the rCF surface, which prevented the fibres from being completely reusable. The study also stated that the lower the pyrolysis temperature, the higher the value of recycled CF. Furthering their previous studies, Shi et al. [58] extended their research to CFRP and GFRP, eliminating the char formation on both recycled $C F$ and GF using chemicals such as detergent, acetone and $\mathrm{N}$-methyl-2-pyrrolidinone (NMP). As a result, the bending strength of rCF increased from 49 to $78 \%$ after treatment with NMP, and the bending strength of rGF increased from 26 to $94 \%$ after treatment with acetone. Recently, Jeong et al. [69] recycled CF and showed $66 \%$ of tensile strength and $100 \%$ of tensile modulus retained from an original value using rapid pyrolysis.

In an attempt to retain maximum tensile strength in the recycled fibres, Ye et al. [70] developed an optimised steam thermolysis process combining vacuum pyrolysis and mild gasification to recycle waste CFRP. The process retained $90 \%$ of tensile strength in both laboratory and semi-industry scales. The study stated that a degradation increase in the polymer matrix resulted in a decrease of the fibres' tensile strength. However, Kim et al. [68] retained $90.42 \%$ of tensile strength compared to the vCF by using a fixed bed reactor at $550{ }^{\circ} \mathrm{C}$ for $60 \mathrm{~min}$. The study mentioned that increasing the steam pyrolysis conditions resulted in improving the removal of char deposited on the fibre surface. In a recent study by Kim et al. [71] superheated steam was used to remove minor resin residues after pyrolysis with carbon dioxide $\left(\mathrm{CO}_{2}\right)$ and recovered above $80 \%$ of the strength compared to vCF. 


\subsubsection{Microwave pyrolysis}

In microwave-assisted pyrolysis, the conventional heating source was replaced with microwave radiation. This change has increased the rate of thermal transfer with minimal energy consumption, without disturbing the primary principle of pyrolysis. The process is capable of recycling both CFRP and GFRP with fibres retaining higher mechanical properties [2]. In a recent study, Obunai et al. [72] achieved a $100 \%$ resin elimination ratio using a $700 \mathrm{~W}$, $2.45 \mathrm{GHz}$, argon atmosphere, and a $2.5 \mathrm{~L} / \mathrm{min}$ flow rate after $300 \mathrm{~s}$. The rCF had only a $0.7 \%$ decrease in tensile strength compared to VCF. Similarly, Jiang et al. [73] recycled CFRP at $500^{\circ} \mathrm{C}$ for $30 \mathrm{~min}$ with a $0.70 \mathrm{~m}^{3} / \mathrm{min}$ nitrogen flow. The rCF possess a clear fibre surface with mechanical properties like virgin fibres.

\subsubsection{Pyrolysis on wind turbine application}

Wind energy is a widely-used renewable energy source [74], for which GFs make an important material contribution to wind turbine manufacturing $[3,5,75]$. In general, the life cycle of an individual wind turbine only lasts from 20 to 25 years [76]. Studies focusing on GF recycling from wind turbine applications have frequently preferred pyrolysis [77]. Apart from the basic GF recycling, studies have focused on retaining their mechanical properties to complete the life-cycle loop by reusing them in various other applications [5].

Looking at early studies related to wind turbine recycling after 2010, studies like Åkesson et al. $[76,77]$ were successful in retaining $75 \%$ of rGF tensile strength by using microwave pyrolysis in a nitrogen atmosphere. Their study proposed that a loss in tensile strength can be overcome by reusing it as a hybrid composite, combining rGF with vGF. In line with the previous study, Åkesson et al. [78] further investigated improving the rGF properties by reinforcing them with polypropylene (PP). The study stated that the use of maleic anhydride grafted PP along with coupling agents improved the mechanical properties, including the flexural strength, tensile strength and Young's modulus.

Studies like Pico et al. [75] and Beauson et al. [74] have highlighted the limitations and mentioned that rGF from wind turbine blades are short, fluffy and randomly oriented. Also, the rGF tensile strength is lower when compared to VGF. However, minor organic contents of the rGF surface are removed by oxidising. As a counter-statement, Jensen and Skelton [3] highlighted the circular economy as a promising way to reuse the recovered fibres in various applications. The study mentioned that, as an outcome of the GENVIND project (a 4-year project carried out by a Danish innovation consortium), a wind turbine will no longer only be renewable in terms of producing energy but also in material reuse. A collaboration between the material supplier, the wind industry and the EoL sector can make this happen easier. A recent study has estimated that, in the future, chemical recycling will be capable of recycling GF, hybrid and CF wind turbine blades with higher efficiency [9].

\section{Chemical recycling}

In a chemical recycling process, the polymeric matrix present in the waste composite is disintegrated by dissolving it into any chemical solution, such as acids, bases and solvents. Normally, suitable chemicals and solvents are chosen based on the nature of the polymer substrate [4, 79], while the solid composites are mechanically grounded before chemical recycling to increase the surface area. Once the polymer matrix is dissolved, the recycled fibres are washed to remove minor surface residue $[1,79]$. Fibres recovered using chemical recycling have retained long fibres with maximum mechanical properties. Plus, the process has a higher resin decomposition ratio [4].

In modern chemical recycling, resin degradation is either achieved using solvents (solvolysis) or water (hydrolysis). In solvolysis, solvents in different conditions (reaction time and concentration) are used to depolymerise or break the polymeric part of a composite. In hydrolysis, resin degradation takes place because of water [1]. Generally, the use of hazardous and concentrated chemicals results in environmental impact [4], so the harmful chemicals are replaced with water and alcohol at supercritical conditions (SC). Besides, the drawback of improper fibre alignment in discontinuous rCF with a length of more than $5 \mathrm{~mm}$ can be suppressed using a centrifugal alignment rig concept [80] or by using calendaring through rollers with $0.10-0.15 \mathrm{~mm}$ gap at $110^{\circ} \mathrm{C}[81]$.

\subsection{Classification of chemical recycling}

Classifying the chemical recycling process on the basis of previous studies depends on structuring significant factors according to its priorities. In early literature, Morin et al. [82] classified chemical recycling (solvolysis) based on temperature; solvolysis at low temperature using solvents like acid solutions, alcohols, etc., at $90^{\circ} \mathrm{C}$ and solvolysis in SC of solvents like acids and water. However, recent research by Oliveux et al. [2] classified solvolysis based on higher temperature and pressure (HTP) with temperature $>200^{\circ} \mathrm{C}$ and lower temperature and pressure (LTP) with temperature $<200^{\circ} \mathrm{C}$. In this study, chemical recycling is organised based on studies of nitric acid, together with 
other chemicals in mild conditions $\left(T<100^{\circ} \mathrm{C}\right)$, and others at higher conditions $\left(\mathrm{T}>100^{\circ} \mathrm{C}\right)$.

\subsubsection{Recycling using nitric acid}

Nitric acid is suitable for recycling both CFRP and GFRP. In the early-stage recycling of CFRP using acids, Liu et al. [83] found that nitric acid performed better in decomposing thermoset epoxy resin and recycled cleaner CFs compared to both sulfuric and hydrochloric acid. Also, orthogonal experimentation was used to prove the reusability of recycled CFs, while even stronger resins like amine cured epoxy were decomposed using nitric acid-for which $\mathrm{Ma}$ et al. [84] achieved a $99.18 \%$ resin decomposition ratio. The study resulted in an $85 \%$ CF cleanliness rate with minimal damage to the fibre surface. Similarly, Lee et al. $[85,86]$ recycled CFs with only a $2.91 \%$ tensile strength decrease compared to vCF. The detailed process conditions are mentioned in Table 2.

GFRP decomposition was also more efficient with nitric acid when compared to concentrated sulfuric acid [87]. In an early study, Yuyan et al. [87] achieved a $99 \%$ rate of resin decomposition. The rGF only has a $3.5-15.1 \%$ tensile strength decrease and a $2.5 \%$ decrease in interlaminar shear strength (ILSS) compared to the original fibres. The study stated that an increase in temperature and acid concentration would increase the decomposition rate. Another study by Dang et al. [88] investigated the corrosion resistance of T-GF and E-GF and stated that T-GF has higher corrosion resistance in nitric acid solution compared to E-GF.

\subsubsection{Recycling using mild conditions}

The chemical recycling of scrap composite using mild conditions increases resin degradation [2]. Studies related to a lower temperature $\left(T<100^{\circ} \mathrm{C}\right)$ and mild acids have also achieved relatively higher results. In Li et al. [89] study, a $90 \mathrm{wt} \%$ epoxy decomposition ratio was achieved using a self-accelerating oxidative decomposition system (acetone + peroxide hydrogen $\left.\left[\mathrm{H}_{2} \mathrm{O}_{2}\right]\right)$. The authors mentioned that acetic acid is used to pre-treat the waste composite for expansion, producing a larger surface area. The rCF retained more than $90 \%$ of tensile strength compared to the original composite and showed that recycling under mild conditions is effective. The detailed process conditions are mentioned in Table 2.

Similarly, Xu et al. [90] achieved a 90\% epoxy decomposition rate using $\mathrm{N}, \mathrm{N}$-dimethylformamide (DMF) and $\mathrm{H}_{2} \mathrm{O}_{2}$ mixed solution. The rCF only shows a $5 \%$ tensile strength decrease compared to the original composite. The single fibre tensile test only showed a $2 \%$ tensile strength loss compared to the vCF after a $10{ }^{\circ} \mathrm{C}$ process temperature increase. In a recent study, Das et al. [91] showed a $97 \%$ resin decomposition ratio from a single-stage oxidation process using an aqueous mixture (AM) of peracetic acids. The $\mathrm{rCF}$ retained $94 \%$ of its original strength. This process is limited to CF, and no proper study was found concerning GF. However, recent studies used solvents such as polyethylene glycol [92], dimethylformamide (DMF) [93] and water $(1 \% \mathrm{NaOH})[94]$ to recycle WPCBs under mild conditions.

\subsubsection{Recycling using higher conditions}

Studies carried out since 2000 have adopted higher process parameters for recycling waste composites with higher resin decomposition, with chemical recycling using super and sub-critical conditions (SCC) playing an essential role in this [2]. However, recycling using super and sub-critical fluids, especially water and alcohol, have been significantly narrowed down (summarised in a separate section). Based on the literature, studies since 2010 have focused more on improving the mechanical properties of recycled fibre. The process parameters, conditions and outcomes of the research are listed in Table 3, with the outcome being

Table 2 Process conditions

\begin{tabular}{lll}
\hline References & Year & Process conditions \\
\hline Liu et al. [83] & 2004 & $70-90{ }^{\circ} \mathrm{C}$ \\
Yuyan et al. [87] & 2006 & $90{ }^{\circ} \mathrm{C}, 8 \mathrm{M}$ nitric acid, $2 \mathrm{~g} / 100 \mathrm{~mL}$ feedstock ratio and $5 \mathrm{~h}$ \\
Ma et al. [84] & 2009 & $95^{\circ} \mathrm{C}, 8 \mathrm{~mol} / \mathrm{L}$ nitric acid and $23 \mathrm{~h}$ \\
Le et al. [85] & 2010 & $90^{\circ} \mathrm{C}, 6 \mathrm{~g}: 100 \mathrm{~mL}$ (weight CFRP: nitric acid) for $5 \mathrm{~h}$ \\
Lee et al. [86] & 2011 & $90^{\circ} \mathrm{C}$, a hexahedral circulating system at a $1 \mathrm{~cm} / \mathrm{s}$ linear flow \\
& & rate, $100 \mathrm{~g}: 1.8 \mathrm{~L}$ (waste composite: $12 \mathrm{M}$ aqueous nitric acid \\
& & ratio) \\
Li et al. [89] & 2012 & $60{ }^{\circ} \mathrm{C}$ for $30 \mathrm{~min}$ \\
Xu et al. [90] & 2013 & $90^{\circ} \mathrm{C}$ for $30 \mathrm{~min}$, hermetic reactor \\
Das et al. [91] & 2018 & $65^{\circ} \mathrm{C}$ for $4 \mathrm{~h}$. AM: 95 vol\% $14 \mathrm{M}$ acetic acid and 5 vol\% $9 \mathrm{M} \mathrm{H}_{2} \mathrm{O}_{2}$ \\
\hline
\end{tabular}


Table 3 Recycling using high conditions after 2010

\begin{tabular}{|c|c|c|c|c|c|}
\hline References & Year & Recycled & Solvents & Parameter & Outcome \\
\hline Lee et al. [85] & 2010 & $\mathrm{CF}$ & $\begin{array}{l}\text { Organic: tetralin }(T) \text { and dieth- } \\
\text { ylene glycol monomethyl } \\
\text { ether (DGME) }\end{array}$ & $\begin{array}{l}350^{\circ} \mathrm{C}, 2 \mathrm{Mpa} \text { for } 2 \mathrm{~h} \\
\mathrm{DGME}, 193^{\circ} \mathrm{C} \text {, atm pressure } \\
\text { (AP) for } 10 \mathrm{~h}\end{array}$ & $\begin{array}{l}3.67 \% \text { decrease in tensile } \\
\text { strength compared to vCF }\end{array}$ \\
\hline Yang et al. [95] & 2014 & $\mathrm{CF} / \mathrm{GF}$ & Polyethylene glycol/NaOH & $\begin{array}{l}200^{\circ} \mathrm{C} \text { for } 4 \mathrm{~h} \text { with } 0.1 \mathrm{~g} \\
\mathrm{NaOH} / \mathrm{g}\end{array}$ & $\begin{array}{l}\text { 84.1-93\% decomposition } \\
\text { efficiency } \\
\text { CF and GF } 4-6 \% \text { decrease in } \\
\text { original tensile strength }\end{array}$ \\
\hline Yamaguchi et al. [96] & 2015 & $\mathrm{CF}$ & Hydrochloric acid (HCL) & $130-150^{\circ} \mathrm{C}, 2 \mathrm{~h}$ & rCF like vCF \\
\hline Nie et al. [97] & 2015 & $\mathrm{CF}$ & Molten $\mathrm{KOH}$ & $285-330^{\circ} \mathrm{C}, \mathrm{AP}$ & Retained $95 \%$ tensile strength \\
\hline Wang et al. [98] & 2015 & GF & $\begin{array}{l}\text { Aluminium chloride/acetic } \\
\qquad \mathrm{AlCl}_{3} / \mathrm{CH}_{3} \mathrm{COOH}\end{array}$ & $180^{\circ} \mathrm{C}$ for $9 \mathrm{~h}$ & Retained $96 \%$ of tensile strength \\
\hline Wang et al. [99] & 2015 & $\mathrm{CF}$ & $\begin{array}{l}\text { Aluminium chloride/acetic } \\
\qquad \mathrm{AlCl}_{3} / \mathrm{CH}_{3} \mathrm{COOH}\end{array}$ & $180^{\circ} \mathrm{C}, 15$ wt $\%$ solvent for $6 \mathrm{~h}$ & $\begin{array}{l}\text { Retained } 97.77 \% \text { of tensile } \\
\text { strength }\end{array}$ \\
\hline Liu et al. [100] & 2017 & $\mathrm{CF}$ & $\mathrm{ZnCl}_{2}$ /ethanol catalyst system & $190^{\circ} \mathrm{C}$ & $\begin{array}{l}\text { Retained high mechanical } \\
\text { property }\end{array}$ \\
\hline Oliveux et al. [101] & 2017 & $\mathrm{CF}$ & $\begin{array}{l}\text { Water and acetone in 20:80 vol } \\
\text { ratio }\end{array}$ & $\begin{array}{l}320^{\circ} \mathrm{C}, 180 \pm 10 \text { bars in a } 5 \mathrm{~L} \\
\text { batch reactor }\end{array}$ & rCF like vCF \\
\hline Wu et al. [102] & 2019 & $\mathrm{CF}$ & Molten $\mathrm{ZnCl}_{2}$ & $360^{\circ} \mathrm{C}, 80 \mathrm{~min}$ & Retained $95 \%$ tensile strength \\
\hline
\end{tabular}

the retaining of maximum mechanical properties with maximum resin decomposition efficiency.

Besides the focus on property improvement, studies have also focused on comparing the recycling mechanisms involved in the chemical recycling process. For example, Ma et al. [103] compared the depolymerisation and also the acid digestion of amine-cured epoxy resin, finding that the resin dissolution rate was influenced not only by the chemical reaction rate but also by the diffusion rate. Working from their previous research, Ma and Nutt [104] were able to implement their findings on both CF and GF to disintegrate amine-cured epoxy resin. The study showed that acid digestion with acetic acid $/ \mathrm{H}_{2} \mathrm{O}_{2}$ at $110^{\circ} \mathrm{C}$ was effective when compared to depolymerisation with benzyl alcohol/ $\mathrm{K}_{3} \mathrm{PO}_{4}$ at $200{ }^{\circ} \mathrm{C}$ for highly crosslinked amine cured epoxy resin. Also, in the case of acid digestion, minor degradation was found on the rGF surface. Plus, exposing GFRP waste above the elevated temperature will result in rGF strength loss [105].

From an economic point of view, WPCBs can be recycled cost-effectively using higher conditions $\left(260^{\circ} \mathrm{C}\right.$ for $10 \mathrm{~min}$ ). Moreover, the ionic liquid ethyl-3-methylimizadolium tetrafluoroborate $\left[\mathrm{EMIM}^{+}\right]\left[\mathrm{BF}_{4}^{-}\right]$used to dissolve the WPCB resin is capable of multiple regenerations and reuse [106, 107]. Recently, cheaper solvents such as water and $1 \mathrm{M}$ aqueous solution of sodium hydroxide $(\mathrm{NaOH})$ have been used to separate WPCBs at higher conditions $\left(280^{\circ} \mathrm{C}\right.$ for $15 \mathrm{~min}$ ) [23].

\subsection{Alternative approaches}

As with every other process, novel chemical recycling approaches have been studied. By unaltering the overall principle involved in the process, studies have made minor changes for better results. As an early example, Kamimura et al. [108] used microwave-enhanced depolymerisation and recycled 51 wt\% of pure GF from FRP waste. In their study, N-Methyl-N-propylpiperidinium bis(trifluoromethylsulfonyl)imide was used as an ionic liquid at $340{ }^{\circ} \mathrm{C}$ for $2 \mathrm{~min}$ to achieve a maximum chemical yield of $80 \%$. The author mentioned that using microwaves resulted in a high fibre yield in a short process time.

Among the recent studies, Sun et al. [109] investigated electrochemical recycling (ECR) using waste CFRP as an anode and a stainless-steel plate (SSP) as a cathode, with a $\mathrm{NaCl}$ solution as the electrolyte. A voltage of $2.6 \mathrm{~V}$ was passed across the electrodes for 21 days to soften the $\mathrm{CF}$ with a $3 \%$ concentration of $\mathrm{NaCl}$. After softening, the fibres are washed under ultrasonic and dried for three days in a $50{ }^{\circ} \mathrm{C}$ environment. The authors highlighted that the energy consumption for recycling CF using the electrochemical process is $2-10 \mathrm{kWh} / \mathrm{Kg}$, and the energy consumption to manufacture vCF is $55-165 \mathrm{kWh} / \mathrm{Kg}$. Similarly, using ECR, Zhu et al. [110] and Chen et al. [111] both retained mechanical properties similar to $v C F$; this method is inexpensive and suitable for large-scale application [111]. Recently, a mechanochemical process (MCP) similar to ECR has been tested [112], but limited information is available regarding the rCF quality. 
Recent approaches also involve ultrasonics, Das and Varughese [113] investigated a sonochemical recycling process by reacting the CFRP waste with dilute nitric acid and $\mathrm{H}_{2} \mathrm{O}_{2}$ under ultrasonics at $60{ }^{\circ} \mathrm{C}$, achieving a $95 \%$ decomposition ratio. The use of ultrasonic increased the decomposition ratio thrice when compared to the same process without ultrasonics. Similarly, Jiang et al. [114] used ultrasonics so that the waste CFRP could be pre-treatment with a nitric acid solution. The pre-treated CFRP was subjected to Macrogel 400 and a potassium hydroxide (KOH) system at $160^{\circ} \mathrm{C}$ for $200 \mathrm{~min}$. The resins are decomposed at a $95 \mathrm{wt} \%$ resin removal rate, and the rCF retained a $95 \%$ tensile strength compared to VCF. The authors highlighted that the process is highly efficient for recycling thermosetting composite materials.

\subsection{Solvolysis using critical conditions}

A fluid (solvent) adopts a high ability to diffuse a soluble substance when its critical temperature and pressure has been reached. It also performs new chemical reactions for decomposition and partial oxidation [115]. Solvolysis using supercritical fluids (SCF) is an emerging waste composite recycling technology, with the recycling process applying to both CFRP and GFRP. The two commonly used fluids in their subcritical and supercritical conditions are water and alcohol [82]. Solvolysis using alcohols is focused on recycling waste CFRP to dissolve the resin and to recover CF. However, there are fewer studies involving GFRP waste recycling.

It is easy to achieve a supercritical state with alcohols as opposed to water [116]. Supercritical alcohols possess good recycling capabilities when used with waste polymer composites. Among all the supercritical alcohols, propanol is better than ethanol and methanol. When comparing methanol, ethanol, acetone, and 1-propanol, research showed that methanol has a low mass-transfer rate under subcritical conditions. On the other hand, 1-propanols three atoms of carbon and high solvation capacity performs better than methanol and ethanol $[115,117]$.

\subsubsection{Alcohol at critical condition}

In an early study of CF recycling, Piñero-Hernanz, GarcíaSerna et al. [117] investigated the resin elimination percentage of four alcohols: methanol, ethanol, 1-propanol, and acetone. The study resulted in $95 \%$ resin degradation under $15 \mathrm{~min}$, with the rCF retaining $85-99 \%$ of its tensile strength. Among the four alcohols used, acetone performed better at a lower temperature. At higher temperature $\left(450{ }^{\circ} \mathrm{C}\right)$, ethanol, 1-propanol and acetone had a maximum resin elimination of $78.8 \mathrm{wt} \%$, and methanol had only $60.2 \mathrm{wt} \%$. However, a later study conducted by Okajima et al. [118] showed that supercritical methanol performed much better when compared to previous studies. The recycled CF using methanol had a crack-free surface with only a $9 \%$ decrease in tensile strength and a $20 \%$ decrease in interfacial strength when compared to vCF. The solvent and process conditions involved in recycling CF are tabulated in Table 4.

In line with their previous research, Okajima et al. [119] studied the effect of eight supercritical solvents-methanol, 1-propanol, 2-propanol, 1-butanol, 2-butanol, tertbutanol, acetone, and methyl ethyl ketone-on dissolving the resin (amine-cured thermosetting epoxy) and recycle CF. Among the eight supercritical solvents, acetone had a higher resin elimination. Moreover, rGF using supercritical acetone obtained $95-99 \%$ resin degradation and retained $89 \%$ of its strength compared to vGF [120]. The resin decomposition efficiency improved with increasing

Table 4 Alcohols at critical conditions (CC)

\begin{tabular}{|c|c|c|c|}
\hline References & Year & Solvent & Conditions \\
\hline Piñero-Hernanz et al. [117] & 2008 & $\begin{array}{l}\text { Methanol, ethanol, } \\
\text { 1-propanol, and } \\
\text { acetone }\end{array}$ & $\begin{array}{l}250-400{ }^{\circ} \mathrm{C} \text {, solvent flow rate of } 1.1-2.5 \mathrm{~kg} \text {-alcohol } / \mathrm{kg} \text {-fibre } / \mathrm{min} \text { and } 0.016- \\
0.50 \mathrm{M} \text { alkali catalyst }(\mathrm{NaOH}, \mathrm{KOH} \text {, and } \mathrm{CsOH}), 15 \mathrm{~min}\end{array}$ \\
\hline \multirow[t]{2}{*}{ Okajima et al. [118] } & 2014 & Methanol & Thermosetting: $270^{\circ} \mathrm{C}$ in a batch reactor $8 \mathrm{Mpa}$ for $90 \mathrm{~min}$ \\
\hline & & & Thermoplastic: $285^{\circ} \mathrm{C}$ in a semi-flow type reactor $8 \mathrm{Mpa}$ for $80 \mathrm{~min}$ \\
\hline Okajima et al. [119] & 2017 & Acetone & $320^{\circ} \mathrm{C}$ with molar density $3.64 \mathrm{~mol} / \mathrm{L}$ after $20 \mathrm{~min}$ \\
\hline Sokoli et al. [120] & 2017 & Acetone & $260-280^{\circ} \mathrm{C}, 55-60 \mathrm{bar}, 1.24-2.1 \mathrm{~g} / \mathrm{mL}$ of composite/solvent ratio \\
\hline Okajima and Sako [121] & 2019 & Acetone & $350^{\circ} \mathrm{C}, 14 \mathrm{Mpa}, 60 \mathrm{~min}, 4.35 \mathrm{~mol} / \mathrm{L}$ density of acetone \\
\hline Jiang et al. [115] & 2007 & Propanol & $300^{\circ} \mathrm{C}, 50$ bars and $10 \mathrm{~min}$ \\
\hline Marsh [116] & 2009 & Propanol & $\begin{array}{l}\text { Semi-continuous flow system at } 350^{\circ} \mathrm{C}, \mathrm{KOH} \text { catalyst flow of } 1.1 \mathrm{~kg} \text { of alcohol per } \\
1 \mathrm{~kg} \text { of fibre/min }\end{array}$ \\
\hline Jiang et al. [123] & 2009 & n-Propanol & Semi-continuous flow reactor at $310^{\circ} \mathrm{C}, 5.2 \mathrm{Mpa}$ \\
\hline Yan et al. [124] & 2014 & 1-Propanol & $320^{\circ} \mathrm{C}$, feedstock ratio $2 \mathrm{~g}$ epoxy resin for $0.2 \mathrm{~L} 1$-propanol, $60 \mathrm{~min}$ \\
\hline Yan et al. [125] & 2016 & 1-Propanol & $320^{\circ} \mathrm{C}, 90 \mathrm{~min}$, no catalysist \\
\hline
\end{tabular}


reaction pressure and acetone density [121]. Similar to Okajima et al. [119], Cheng et al. [122] analysed the degradation capability of different supercritical fluids. The study showed that supercritical n-butanol had the highest resin degradation and retained $98 \%$ of tensile strength compared to the original CF. Supercritical acetone holds the second position for resin degradation followed by ethanol and n-propanol. However, at a temperature range between 340 and $360^{\circ} \mathrm{C}$, n-propanol showed a greater capability for resin degradation compared to ethanol. Overall, both supercritical methanol and isopropanol performed poorly in resin degradation.

Among all the alcohols, propanol is a short chain and affordable. CF recycled using propanol achieves a $98 \%$ resin removal rate [116]. The rCF have only a $1 \%$ decrease in interfacial shear strength and a 5.43\% decrease in tensile property compared to vCF [115]. Plus, the rCF offers properties equal to VCF and can be used as its replacement [116]. Like propanol, both n-propanol and 1-propanol also showed promising results. The rCF using $n$-propanol only shows a $0.3-2 \%$ decrease in tensile strength compared to the initial material used [123], whereas the rCF using 1-propanol had the same tensile strength compared to the CF prior to recycling. Also, adding $1 \mathrm{wt} \%$ of $\mathrm{KOH}$, along with 1-propanol, enhances the decomposition ratio of the resin and improves the mechanical stability of rCF [124]. Adding catalysis is not necessary, as the rCF using 1-propanol as a solvent retained $90-95 \%$ tensile strength compared to CF before recycling without any catalyst addition [125].

\subsubsection{Water at critical condition}

Unlike solvolysis using alcohols, waste CFRP and GFRP are both capable of recycling using water at CC. Moreover, considering the number of studies, this section is divided into two to separate those based on CF and those based on GF. Recycling waste CFRP and GFRP using water at CC has resulted in a higher resin decomposition rate along with higher mechanical properties.

4.3.2.1 Based on carbon fibre Following their CF recycling studies using alcohols at CC [117], in the same year (2008), Piñero-Hernanz et al. [126] recycled CF using water at its supercritical condition. The study resulted in a resin removal efficiency of 95.4 wt $\%$ with only a $2-10 \%$ tensile strength decrease of rCF compared to VCF. The addition of alkali catalyst $(\mathrm{NaOH})$ increases the resin removal efficiency [126, 127]. In 2012, when repeating the same approach without any change in the process parameters, Knight et al. [128] achieved a resin decomposition rate of 95.9-99.2 wt\% and recycled woven based CF using supercritical water (deionised water). The rCF shows no tensile strength decrease compared to the original composite.
However, in studies focused on maximum resin decomposition efficiency, Yuyan et al. [129] achieved the highest resin decomposition rate of $100 \mathrm{wt} \%$ by reducing water from a supercritical state to its subcritical state. The rCF only show a $1.8 \%$ tensile strength decrease compared to vCF. Similarly, Kim et al. [130] were able to achieve a 99.5\% resin removal efficiency.

Contradicting the studies with higher resin decomposition ratio, Bai et al. [131] research concluded that the decomposition ratio increase above $96.5 \mathrm{wt} \%$ in recycling CF would decrease the recycled fibre strength, indicating the damage to the fibre surface after complete resin removal. In that study, the authors managed to obtain an 85 wt $\%$ decomposition ratio by using supercritical water and adding oxygen as a catalyst. In recycling CF using water at CC, catalysts play an important role in boosting the resin decomposition ratio [126]. To analyse, this phenomenon, Okajima et al. [132] investigated the resin degradation with a catalyst ( $2.5 \mathrm{wt} \%$ potassium carbonate) and without a catalyst using subcritical water as a solvent. The catalyst process had a better outcome with only a $15 \%$ tensile strength decrease of rCF compared to vCF. However, recent studies have avoided the use of a catalyst, increasing temperature and pressure to maintain higher process efficiency instead $[130,133]$. The studies based on the catalyst are summarised in Table 5 .

The process development after achieving a higher decomposition ratio resulted in studies comparing various solvents with water, in which Yildirir et al. [134] compared ethylene glycol $(E G) /$ water mixture to $E G$ at its near-critical condition. The resin removal was $97.6 \%$ with $\mathrm{EG}$ /water and 92.1\% with EG. The rCF had tensile strength similar to vCF. Similarly, Ibarra et al. [135] studied the resin degradation system to compare water and benzyl alcohol at SC and SCC. The authors observed an initial delamination in the system with thin layers of resin-binding the fibres together and stated that the increased reaction resulted in the complete degradation of these thin resin layers to recycle CF. The decomposition ratio achieved was $90 \%$ from benzyl alcohol and $80 \%$ from water. In the recent scenario, a mixture of acetone/water at CC is used as a solvent, with the results showing a maximum resin elimination of $95 \%$ and successfully closing the rCF life-cycle loop $[133,136,137]$.

4.3.2.2 Based on glass fibre In the recycling of GF using water at CC as a solvent, the solvents degree of fractionation increased whenever there was a substantial increase in any of the following three conditions: catalyst/solvent ratio, solvent/FRP ratio, and reaction temperature [138]. Similarly, the increase in reaction time resulted in a decrease in the mechanical property of the recovered GF. At-lower reaction temperature, the strength loss in rGF is lower and gradually raised with an increase in reaction temperature. A final 
Table 5 The catalyst used to recycle CF

\begin{tabular}{|c|c|c|c|}
\hline References & Year & Catalyst & Condition \\
\hline Piñero-Hernanz et al. [126] & 2008 & $\mathrm{KOH}$ (alkali catalyst) & $400^{\circ} \mathrm{C}, 28 \mathrm{Mpa}, 0.5 \mathrm{M}$ of $\mathrm{KOH}$ \\
\hline Knight et al. [128] & 2012 & $\mathrm{KOH}$ (alkali catalyst) & $410^{\circ} \mathrm{C}, 28 \mathrm{Mpa}$ for $120 \mathrm{~min}$ and $0.5 \mathrm{M} \mathrm{KOH}$ catalyst \\
\hline Yuyan et al. [129] & 2009 & Sulfuric acid & $\begin{array}{l}260^{\circ} \mathrm{C}, 1 \mathrm{M} \text { sulfuric acid, solvent feedstock ratio of } 1: 5 \mathrm{~g} / \\
\mathrm{mL} \text { for } 105 \mathrm{~min}\end{array}$ \\
\hline Kim et al. [130] & 2019 & No catalyst & $400^{\circ} \mathrm{C}, 280 \mathrm{Mpa}$ reactor pressure \\
\hline Bai et al. [131] & 2010 & Oxygen & $440^{\circ} \mathrm{C}, 30 \mathrm{Mpa}$ for $30 \mathrm{~min}$ \\
\hline Okajima et al. [132] & 2011 & Potassium carbonate & $400^{\circ} \mathrm{C}, 20 \mathrm{Mpa}, 2.5 \mathrm{wt} \%$ potassium carbonate for $45 \mathrm{~min}$ \\
\hline Yildirir et al. [134] & 2014 & Water & $\begin{array}{l}400^{\circ} \mathrm{C} \text { ethylene glycol }(\mathrm{EG}) \text { near-critical condition gly- } \\
\text { col/water ratio }(\mathrm{mL} / \mathrm{mL}) \text { of } 5\end{array}$ \\
\hline Keith et al. [133] & 2019 & No catalyst & $320-380^{\circ} \mathrm{C}, 20-30 \mathrm{Mpa}$ for $120-150 \mathrm{~min}$ \\
\hline Keith et al. [136] & 2019 & $\begin{array}{l}0.05 \mathrm{M} \mathrm{ZnCl}_{2} \text { and } \\
\quad \mathrm{MgCl}_{2} / 0.005 \mathrm{M} \mathrm{AlCl}_{3}\end{array}$ & $300{ }^{\circ} \mathrm{C}$ for $45 \mathrm{~min}$ \\
\hline
\end{tabular}

wash to the recycled GF with organic solvents is required to improve the feasibility of the process [139], as well as to increase the delaminating mechanism in recycling WPCBs to allow for GF recycling. A minor per cent (7 vol\%) of water below its critical point can result in higher resin decomposition efficiency [140].

Like any other recycling process for $\mathrm{GF}$, this process also suffered from char formation on the surface of the fibre, due to the gas condensation during hydrolysis. However, initial physicochemical mechanisms such as osmotic cracking, swelling and delaminating can be used to overcome the limitation [141]. In addition to the limitation, the resin structure of the waste GFRP is capable of influencing the rate of hydrolysis, and the hydrolysis mechanism tends to become unstable with varying results [142]. To control the hydrolysis mechanism, Liu et al. [25] used $\mathrm{H}_{2} \mathrm{O}_{2}(9.04 \mathrm{~mL})$ / $\mathrm{NaOH}(0.21 \mathrm{~g})$ along with supercritical water. The process resulted in $95.14 \%$ resin decomposition efficiency with stable hydrolysis throughout the process.

A recent study by Sokoli et al. [120] showed a contradictory use of water as a solvent for recycling GF below its critical point. The author explains that water reacts with alkali oxides on the GF surface and produces micro-cracks. The rGF had a $50-65 \%$ strength loss compared to vGF. Findings also showed that supercritical acetone is capable of completely degrading resins at $260^{\circ} \mathrm{C}$ with $60 \mathrm{bar}$ and $\mathrm{c} / \mathrm{s}$ ratio up to $2.1 \mathrm{~g} / \mathrm{mL}$. The rGF retained $89 \%$ of its tensile strength in comparison to vGF.

\section{Life-cycle analysis}

Compared to $\mathrm{CF}$, GF has contributed to the most global fibre production, which means the percentage of GFRP waste for recycling is higher compared to the percentage of CFRP waste. Surprisingly, studies have focused more on recycling CFRP waste due to its expensive price range and ability to retain maximum mechanical properties after recycling $[7,143]$. A recent study by Hermansson et al. [144] suggested that, in the future, replacing polyacrylonitrile (PAN) with lignin as a raw material for CF will result in lowering the energy use and environmental impact at the time of recycling the waste CFRP.

However, looking at the existing CFRP waste recycling methods, the approaches can be divided into two major techniques. A cheap option; namely landfilling and incineration (approach 1), in which the fibres are not recovered and cause a high negative impact on the environment, including an economic loss in neglecting to reuse the valuable fibres. The second type (approach 2 ) is a profitable and fibre recovery method such as mechanical, chemical and thermal recycling $[4,48]$. Even though the second approach needs capital investment and specific technologies to preserve sustainability, it has a lower environmental impact with a maximum recovery rate of fibres from waste composite. The studies related to the second approach can also be implemented to recycle GFRP waste, as both forms of waste (CFRP and GFRP) involve similar polymer structures [48]. 
LCA studies have emerged from comparing various recycling methods. Among all the LCA indicators, three examples, namely global warming potential (GWP), human toxicity (USETox) and acidification (AE), are identified as essential [145]. However, a GWP indicator is directly associated with environmental change. It was also noted that the cost of recycling and GWP impacts are inversely proportional to each other. When the GWP decreased, so did the cost [146]. In an attempt to analyse the relationship between GWP and cost, Dong et al. [48] studied the waste management of CFRP concerning economic and environmental aspects. The study highlighted that none of the recycling techniques were able to reduce both the recycling cost and GWP impacts simultaneously.

\subsection{Alternative to landfilling and incineration}

Industrial-scale recycling highlights that the energy $(0.27-2.03 \mathrm{MJ} / \mathrm{kg})$ required to recycle CF by mechanical recycling is lower compared to the energy required (183-286 MJ/kg) to manufacture vCF. Also, mechanical recycling via the milling process has a low environmental impact compared to vCF manufacturing [147]. In addition to this, when comparing landfilling and incineration with mechanical recycling methods, landfilling suffers from several taxations and incineration has a high environmental impact due to its massive carbon emissions. The carbon footprint in mechanical recycling is low compared to landfilling and incineration and, even though mechanical recycling involves high recycling cost with low revenue, targeting a higher rCF market can improve its revenue [11]. Moreover, to have an immediate rGF solution from wind turbine blades [9] and EoL WPCBs [8] mechanical recycling can be adapted, which will reduce $90 \%$ of the landfilling net impact [9].

Recent studies have attempted to compare pyrolysis $[10,14]$, chemical recycling [12], water at CC [10, 13] and EDF [10] with landfilling and incineration. These studies have chiefly focused on showcasing the environmental and economic values of using recycling methods involving fibre recovery. The LCA indicators strongly support pyrolysis over landfilling and incineration. In particular, the low environmental impact and low energy consumption to $\mathrm{rCF}$, which even supports $\mathrm{rCF}$ over vCF $[10,14]$. Results from the ReCiPe midpoint method supports chemical recycling over landfilling, with an average of $80 \%$ in all possible LCA indicators [12]. Results from CML-IA baseline and ILCD 2011 midpoint LCA methods show that recycling CFRP under landfilling and incineration possesses a $25-30 \%$ environmental impact and $25 \%$ additional energy consumption compared to recycling using water at CC [13].

\subsection{Pyrolysis and chemical recycling process}

Further recycling process development focusing on fibre recovery leads to comparisons of environmental and economic aspects within the approach to identify various recycling methods that support sustainability. In 2010, to replace train car bodies in South Korea with CFRP, Lee et al. [85] investigated the identification of environmentally-friendly recycling methods and compared chemical recycling with pyrolysis. The study concluded that the energy footprints of chemical recycling (7.62 MJ-eq) are six times less compared to pyrolysis ( $47.88 \mathrm{MJ}$-eq), and the greenhouse gas (GHG) emissions of chemical recycling (1196.22 $\mathrm{g} \mathrm{CO}_{2}$-eq) was five times less (5916.08 $\mathrm{g} \mathrm{CO}_{2}$-eq). Overall, these findings support chemical recycling over pyrolysis.

Similarly, results from an LCA study of La Rosa et al. [148] was favourable for recycling CF using chemical recycling, which involved less energy consumption and lowered environmental impacts compared to manufacturing vCF. The study stated that reducing material and energy consumption during product manufacturing can be a game changer for environmental benefits. The EoL wind turbine blades are also favourable for the chemical recycling process. However, if the recyclate value drops to $47 \%$ or processing energy increases above $35 \mathrm{MJ} / \mathrm{kg}$, then using chemical recycling is worthless [9].

\subsection{Pyrolysis and solvolysis using SCF}

In contrast to Lee et al. [85], a Khalil [149] 2018 study used GaBi LCA software and showed opposite results, in which conventional thermolysis via pyrolysis and solvolysis using supercritical water (SCW) was compared. The study showed that the solvolysis process had a 78 times greater human health impact, 76 times greater ecotoxicity, 17 times greater carbon footprint (global warming) and 3 times greater ozone depletion when compared to pyrolysis. Also, the quantitative evidence proves that CFRP recycling via pyrolysis had the advantage of positive environmental and human health value compared to solvolysis using SCW.

Furthermore, Khalil [150] analysed different solvolysis methods using GaBi LCA software. The study covered supercritical fluids such as water, methanol, ethanol, 1-butanol, 1-propanol, acetone, ethylene glycol and binary mixtures of solvents and water. The results showed that binary mixtures of solvent and water were capable of recycling quality CF and had lower production costs, environmental and human health impacts compared to the use of pure solvents at CC. Plus, this could be a promising method for closing the life-cycle loop of CFRP waste. 


\subsection{Fluidised bed process}

Several LCA studies on FBP by Meng et al. [16, 151-153], in 2017 and 2018, resulted in a better understanding of the process. The studies showed that replacing vCF with rCF can reduce global warming potential (GWP) by $33-51 \%$ and primary energy demand (PED) by $32-50 \%$ [153]. Similarly, replacing traditional materials (steel and aluminium) with rCF in the automotive (components) application showed potential improvement and environmental benefits [152]. As well as the environmental benefits, a hypothetical commercial-scale FBP design with conditions: $100-6000 \mathrm{t} / \mathrm{y}$ plant capacity and $3-12 \mathrm{~kg} / \mathrm{h} \mathrm{m}^{2}$ feed rate can recover $\mathrm{CFs}$ at a rate of $5 \mathrm{USD} / \mathrm{Kg}$, which means the recycling costs of CF are $15 \%$ of the overall vCF manufacturing cost. Therefore, it is clear that reusing has a positive environmental outcome along with economic profit [151]. Finally, when comparing the FBP to pyrolysis and chemical recycling using LCA indicators, FBP has a lower PED, GWP and power consumption. Overall, a significant amount of environmental and cost-benefits can be achieved by adapting FBP [16].

\section{Discussion}

In the current scenario, waste has become a valuable raw material. Based on the literature analysis of rCF and rGF, the scientific community and composite industries are highly focused on recycling techniques to recover fibres completely. Government policies play a significant role in such a drastic change. Strategies such as implementing a hefty tax on composite industries for environmental degradation, the EU policy towards commercial EoL components, economic-based calculations over composite waste and quantity-based estimations over composite waste from the US and the UK, are guiding the composite market to close the life-cycle loop of waste fibres through sustainable recycling. Additionally, EoL composite waste based on applications of the aeronautical/-aerospace sector, the renewable energy sector, and the automotive sector is enormous in volume. These cumulating wastes should be recycled in an industrial-scale.

There is a considerable need to determine such an industrial-scale process and further develop it into a sustainable method to achieve a higher yield in fibre recovery. This can be gradually achieved by briefly analysing the previous studies. In which, economic-based literature proposes that the energy consumption in fibre recycling using any recycling technique is lower when compared to the energy required to manufacture virgin fibres. The profitable selling price for both the recycled CF and GF with only a minor compromise in the quality of the fibres can compete with the expensive virgin fibres available in the market. Supporting this statement, Recycling-based literature proposes that replacing virgin fibres with recycled fibres is highly possible in various applications. On the other hand, environmental-based literature takes a controversial approach in stating that environmental values are inversely proportional to recycling industry profit margins. Overall, considering recycled fibres as an alternative to virgin fibres is a sustainable way to manage the cumulating CFRP and GFRP waste.

When considering the reusability of recycled fibres in various applications, the recycled fibres are either used directly or reinforced with a minimal percentage of virgin fibres (hybrid composite) to negotiate minor strength loss. These scenarios are entirely dependent on the end application and the commercial possibilities of a composite market. Recent studies focus on applications that function based on a complete replacement of virgin fibres by recycled fibres. The outcomings will benefit the growth of the recycling market and reduce the exponential growth in tonnes of EoL waste.

Overall, specific research gaps have been identified as a result of this study.

1. Alternative approaches mentioned in mechanical recycling and chemical recycling, such as recycling using high voltage and electricity. Further research in these studies can lead to cost-effective recycling processes in short time intervals, along with a low environmental impact. It can also be used as a pre-recycling process for initial separation during commercial-scale recycling.

2. In the thermal-based recycling process, using microwaves as an alternative source of heat reduces both the energy consumption and the recycling time in half compared to traditional heat sources available. Further research in the field can avoid unwanted heat-loss in industrial-scale recycling, considering huge structures to be recycled such as aeroplane and windmill parts.

3. Extensive researches are needed to transforming laboratory-scale solvolysis using water at CC (solvent) and binary solvent mixture (water + solvent) at CC into a fully functional commercial scale. This will benefit the recycling industries.

4. LCA studies contribute to major factors in understanding the pros and cons of the various recycling process, further studies to support the circular economy to show re-manufacturing as a significant player in closing the life-cycle loop of the recycled fibres are required. After all, reusing the recovered fibres in actual applications is the only possible way to suppress the need to manufacture virgin fibres. 


\section{Conclusion}

The main goal of the current study is to determine various recycling techniques for CFRP and GFRP waste and prioritise the sustainably identified recycling methods based on economic and environmental values. A critical comparison was carried out based on factors such as process conditions, process outcomes, mechanical properties, ease of reuse, environmental impact and cost-effectiveness. However, the research has been narrowed down further to focus on completely recovering the valuable fibres by adapting recycling techniques such as mechanical recycling, thermal recycling, and chemical recycling. Plus their advantages and disadvantages were discussed briefly. Furthermore, to support the credibility of these techniques, LCA studies were included in comparing the environmental and economic aspects of the recycling techniques. Overall, this study promotes a circular economic approach to close the life-cycle loop of both CF and GF composite wastes into re-manufactured composites.

Currently, the fate of scarp and EoL CFRP and GFRP is mostly to become landfill or to be sent for incineration, being the methods adopted by conventional waste disposal industries. However, taking on board factors such as climate change, global warming, and a sustainable alternative and circular economy, waste disposal industries have recently shifted to complete fibre recovery methods. This change is occurring due to the immense contribution of studies focusing on recycling CFRP and GFRP waste. These studies are briefly discussed in this review article, and the outcomes are summarised below.

1. Landfilling and incineration methods of disposing of CFRP and GFRP waste are not sustainable approaches anymore and have to be completely shut-down without any further analysis.

2. Mechanical recycling techniques have reached their maximum exploration, losing status as a primary recycling method and becoming a pre-recycling process for other techniques such as thermal and chemical recycling. Also, alternative approaches to breaking down the waste composite using high voltage are becoming more attractive than traditional mechanical recycling.

3. Commercial-scale FBP is capable of recycling clean and high-quality fibres with a fraction of the energy consumption needed to manufacture virgin fibres. Also, the process has a low environmental impact and a decent commercial-scale profit margin. However, the fibres are fluffy and discontinuous, limiting attitudes toward ease of reuse.
4. Commercial-scale pyrolysis has been successfully adopted in Germany and the UK. The process implements green values by recycling fibres along with products such as gas and liquid, which can be further used as feedstocks. However, char formation in rGFs and retaining the complete mechanical properties of both CF and GF are challenging. Besides, the recycled fibres need a secondary heat/chemical treatment to eliminate minor resin impurities.

5. Traditional chemical recycling using strong acids or solvents at various conditions has severe environmental impacts. Even though the process is capable of recycling high quality and clean fibres with a crackfree surface and low energy usage, the disposal of such strong solvents is challenging. However, alternative approaches such as electrochemical recycling look promising but are still at the laboratory stage.

6. A chemical recycling process using solvents such as water at $\mathrm{CC}$ and a binary fraction of mild solvents with water at CC is considered to be the future of recycling both CFRP and GFRP waste. The maximum resin elimination ratio, the higher retention of mechanical properties in recycled fibres and the use of cheap and sustainable solvents make the process distinct from any other recycling process. However, the process is not yet commercialised, and critical operating conditions tend to consume additional energy.

The future aims of our research team are to study both recycled CFRP and GFRP from industrial waste. The research will be focused on analysing the recyclability of the recovered fibre, on the mechanical properties after reuse, on the possible applications to implement the remanufactured composite and, finally, on an analysis of how to close its life-cycle loop. The composite wastes will be recycled by thermolysis in a pyrolytic reactor. Also, compression moulding method will be adopted to re-manufacture the covered fibres with polymers.

Acknowledgements Open access funding provided by LUT University.

Author's contribution Both the authors contributed to the study conception and design. Material preparation, data collection and manuscript writing were performed by Sankar Karuppannan Gopalraj. Data selection and structuring were performed by Timo Kärki. Comments and corrections from Timo Kärki are incorporated with all previous versions of the manuscript written by Sankar Karuppannan Gopalraj. This final draft of the manuscript has been read and approved by both the authors without any conflict of interest.

\section{Compliance with ethical standards}

Conflict of interest The authors declare that they have no competing interests. 
Open Access This article is licensed under a Creative Commons Attribution 4.0 International License, which permits use, sharing, adaptation, distribution and reproduction in any medium or format, as long as you give appropriate credit to the original author(s) and the source, provide a link to the Creative Commons licence, and indicate if changes were made. The images or other third party material in this article are included in the article's Creative Commons licence, unless indicated otherwise in a credit line to the material. If material is not included in the article's Creative Commons licence and your intended use is not permitted by statutory regulation or exceeds the permitted use, you will need to obtain permission directly from the copyright holder. To view a copy of this licence, visit http://creativecommons .org/licenses/by/4.0/.

\section{References}

1. Asmatulu E, Twomey J, Overcash M (2014) Recycling of fiberreinforced composites and direct structural composite recycling concept. J Compos Mater 48:593-608

2. Oliveux G, Dandy LO, Leeke GA (2015) Current status of recycling of fibre reinforced polymers: review of technologies, reuse and resulting properties. Prog Mater Sci 72:61-99

3. Jensen JP, Skelton K (2018) Wind turbine blade recycling: experiences, challenges and possibilities in a circular economy. Renew Sustain Energy Rev 97:165-176

4. Pimenta S, Pinho ST (2011) Recycling carbon fibre reinforced polymers for structural applications: technology review and market outlook. Waste Manag 31:378-392

5. Cousins DS, Suzuki Y, Murray RE et al (2019) Recycling glass fiber thermoplastic composites from wind turbine blades. J Clean Prod 209:1252-1263

6. Yao S-S, Jin F-L, Rhee KY et al (2018) Recent advances in carbonfiber-reinforced thermoplastic composites: a review. Compos B Eng 142:241-250

7. Bachmann J, Hidalgo C, Bricout S (2017) Environmental analysis of innovative sustainable composites with potential use in aviation sector-a life cycle assessment review. Sci China Technol Sci 60:1301-1317

8. Hadi P, Ning C, Ouyang W et al (2015) Toward environmentallybenign utilization of nonmetallic fraction of waste printed circuit boards as modifier and precursor. Waste Manag 35:236-246

9. Liu P, Meng F, Barlow CY (2019) Wind turbine blade end-of-life options: an eco-audit comparison. J Clean Prod 212:1268-1281

10. Pillain B, Loubet P, Pestalozzi F et al (2019) Positioning supercritical solvolysis among innovative recycling and current waste management scenarios for carbon fiber reinforced plastics thanks to comparative life cycle assessment. J Supercrit Fluids 154:104607. https://doi.org/10.1016/j.supflu.2019.104607

11. Li X, Bai R, McKechnie J (2016) Environmental and financial performance of mechanical recycling of carbon fibre reinforced polymers and comparison with conventional disposal routes. J Clean Prod 127:451-460

12. Prinçaud M, Aymonier C, Loppinet-Serani A et al (2014) Environmental feasibility of the recycling of carbon fibers from CFRPs by solvolysis using supercritical water. ACS Sustain Chem Eng 2:1498-1502

13. Nunes AO, Viana LR, Guineheuc P-M et al (2018) Life cycle assessment of a steam thermolysis process to recover carbon fibers from carbon fiber-reinforced polymer waste. Int J Life Cycle Assess 23:1825-1838

14. Witik RA, Teuscher R, Michaud V et al (2013) Carbon fibre reinforced composite waste: an environmental assessment of recycling, energy recovery and landfilling. Compos A Appl Sci Manuf 49:89-99

15. Naqvi SR, Prabhakara HM, Bramer EA et al (2018) A critical review on recycling of end-of-life carbon fibre/glass fibre reinforced composites waste using pyrolysis towards a circular economy. Resour Conserv Recycl 136:118-129

16. Meng F, Olivetti EA, Zhao Y et al (2018) Comparing life cycle energy and global warming potential of carbon fiber composite recycling technologies and waste management options. ACS Sustain Chem Eng 6:9854-9865

17. Moriyama A, Hasegawa T, Nagaya C et al (2019) Assessment of harmfulness and biological effect of carbon fiber dust generated during new carbon fiber recycling method. J Hazard Mater 378:120777. https://doi.org/10.1016/j.jhazmat.2019.120777

18. Roberts T (2007) Rapid growth forecast for carbon fibre market. Reinf Plast 51:10-13

19. Lefeuvre A, Garnier S, Jacquemin L et al (2017) Anticipating in-use stocks of carbon fiber reinforced polymers and related waste flows generated by the commercial aeronautical sector until 2050. Resour Conserv Recycl 125:264-272

20. Lefeuvre A, Garnier S, Jacquemin L et al (2019) Anticipating in-use stocks of carbon fibre reinforced polymers and related waste generated by the wind power sector until 2050. Resour Conserv Recycl 141:30-39

21. The European Wind Energy Association (2014) Research note outline on recycling wind turbines blades. http://www.ewea. org/fileadmin/files/our-activities/policy-issues/environment/ research_note_recycling_WT_blades.pdf. Accessed 15 Feb 2019

22. Mamanpush SH, Li H, Englund K et al (2018) Recycled wind turbine blades as a feedstock for second generation composites. Waste Manag 76:708-714

23. Pinho S, Ferreira M, Almeida MF (2018) A wet dismantling process for the recycling of computer printed circuit boards. Resour Conserv Recycl 132:71-76

24. Long L, Sun S, Zhong S et al (2010) Using vacuum pyrolysis and mechanical processing for recycling waste printed circuit boards. J Hazard Mater 177:626-632

25. Liu K, Zhang Z, Zhang F-S (2016) Advanced degradation of brominated epoxy resin and simultaneous transformation of glass fiber from waste printed circuit boards by improved supercritical water oxidation processes. Waste Manag $56: 423-430$

26. Shen $Y$ (2018) Effect of chemical pretreatment on pyrolysis of non-metallic fraction recycled from waste printed circuit boards. Waste Manag 76:537-543

27. Mohamed Sultan AA, Mativenga PT (2019) Sustainable location identification decision protocol (SuLIDeP) for determining the location of recycling centres in a circular economy. J Clean Prod 223:508-521

28. McConnell VP (2010) Launching the carbon fibre recycling industry. Reinf Plast 54:33-37

29. Vieira DR, Vieira RK, Chang ChainM (2017) Strategy and management for the recycling of carbon fiber-reinforced polymers (CFRPs) in the aircraft industry: a critical review. Int J Sustain Dev World Ecol 24:214-223

30. Job S (2013) Recycling glass fibre reinforced compositeshistory and progress. Reinf Plast 57:19-23

31. Pillain B, Viana LR, Lefeuvre A et al (2019) Social life cycle assessment framework for evaluation of potential job creation with an application in the French carbon fiber aeronautical recycling sector. Int J Life Cycle Assess 24:1729-1742

32. Green BN, Johnson CD, Adams A (2006) Writing narrative literature reviews for peer-reviewed journals: secrets of the trade. J Chiropr Med 5:101-117 
33. Pickering SJ (2006) Recycling technologies for thermoset composite materials-current status. Compos A Appl Sci Manuf 37:1206-1215

34. Palmer J, Ghita OR, Savage L et al (2009) Successful closedloop recycling of thermoset composites. Compos A Appl Sci Manuf 40:490-498

35. Nekouei RK, Pahlevani F, Rajarao R et al (2018) Two-step pre-processing enrichment of waste printed circuit boards: mechanical milling and physical separation. J Clean Prod 184:1113-1124

36. Wang $H$, Zhang G, Hao J et al (2018) Morphology, mineralogy and separation characteristics of nonmetallic fractions from waste printed circuit boards. J Clean Prod 170:1501-1507

37. Wong K, Rudd C, Pickering S et al (2017) Composites recycling solutions for the aviation industry. Sci China Technol Sci 60:1291-1300

38. Mou P, Wa L, Xiang D et al (2004) A physical process for recycling and reusing waste printed circuit boards. In: IEEE international symposium on electronics and the environment, $\mathrm{pp}$ 237-242

39. Meira Castro AC, Carvalho JP, Ribeiro MCS et al (2014) An integrated recycling approach for GFRP pultrusion wastes: recycling and reuse assessment into new composite materials using Fuzzy Boolean Nets. J Clean Prod 66:420-430

40. Shuaib NA, Mativenga PT (2016) Effect of process parameters on mechanical recycling of glass fibre thermoset composites. Procedia CIRP 48:134-139

41. Kočevar G, Kržan A (2018) Recycling of an acrylate-glass fiber reinforced polyester composite. J Mater Cycles Waste Manage 20:1106-1114

42. Li H, Englund K (2017) Recycling of carbon fiber-reinforced thermoplastic composite wastes from the aerospace industry. J Compos Mater 51:1265-1273

43. Roux M, Dransfeld C, Eguémann N, et al (2014) Processing and recycling of a thermoplastic composite fibre/peek aerospace part. In: 16th European conference on composite materials, ECCM 2014. Seville

44. Roux M, Eguémann N, Dransfeld C et al (2017) Thermoplastic carbon fibre-reinforced polymer recycling with electrodynamical fragmentation: from cradle to cradle. J Thermoplast Compos Mater 30:381-403

45. Mativenga PT, Shuaib NA, Howarth J et al (2016) High voltage fragmentation and mechanical recycling of glass fibre thermoset composite. CIRP Ann Manuf Technol 65:45-48

46. Oshima K, Matsuda S, Hosaka M et al (2020) Rapid removal of resin from a unidirectional carbon fiber reinforced plastic laminate by a high-voltage electrical treatment. Sep Purif Technol 231:115885. https://doi.org/10.1016/j.seppur.2019.115885

47. Rodrigues GGM, Faulstich De Paiva JM, Braga Do Carmo J et al (2014) Recycling of carbon fibers inserted in composite of DGEBA epoxy matrix by thermal degradation. Polym Degrad Stab 109:50-58

48. Vo Dong PA, Azzaro-Pantel C, Cadene A-L (2018) Economic and environmental assessment of recovery and disposal pathways for CFRP waste management. Resour Conserv Recycl 133:63-75

49. Thomason JL, Nagel U, Yang L et al (2016) Regenerating the strength of thermally recycled glass fibres using hot sodium hydroxide. Compos A Appl Sci Manuf 87:220-227

50. Yang L, Sáez ER, Nagel U et al (2015) Can thermally degraded glass fibre be regenerated for closed-loop recycling of thermosetting composites? Compos A Appl Sci Manuf 72:167-174

51. Nagel U, Yang L, Kao CC et al (2018) Effects of thermal recycling temperatures on the reinforcement potential of glass fibers. Polym Compos 39:1032-1040

52. Pender K, Yang L (2017) Investigation of the potential for catalysed thermal recycling in glass fibre reinforced polymer composites by using metal oxides. Compos A Appl Sci Manuf 100:285-293

53. Pickering SJ, Kelly RM, Kennerley JR et al (2000) A fluidised-bed process for the recovery of glass fibres from scrap thermoset composites. Compos Sci Technol 60:509-523

54. Pickering SJ, Turner TA, Meng F, et al (2015) Developments in the fluidised bed process for fibre recovery from thermoset composites. In: CAMX 2015-Composites and advanced materials expo. pp 2384-2394

55. Zheng Y, Shen Z, Ma S et al (2009) A novel approach to recycling of glass fibers from nonmetal materials of waste printed circuit boards. J Hazard Mater 170:978-982

56. Pender K, Yang L (2019) Investigation of catalyzed thermal recycling for glass fiber-reinforced epoxy using fluidized bed process. Polym Compos 40:3510-3519

57. Yip HLH, Pickering SJ, Rudd CD (2002) Characterisation of carbon fibres recycled from scrap composites using fluidised bed process. Plast Rubber Compos 31:278-282

58. Shi J, Bao L, Kobayashi R et al (2012) Reusing recycled fibers in high-value fiber-reinforced polymer composites: improving bending strength by surface cleaning. Compos Sci Technol 72:1298-1303

59. Limburg M, Stockschläder J, Quicker P (2019) Thermal treatment of carbon fibre reinforced polymers (Part 1: recycling). Waste Manage Res 37:73-82

60. Mazzocchetti L, Benelli T, D'Angelo E et al (2018) Validation of carbon fibers recycling by pyro-gasification: the influence of oxidation conditions to obtain clean fibers and promote fiber/matrix adhesion in epoxy composites. Compos A Appl Sci Manuf 112:504-514

61. Onwudili JA, Miskolczi N, Nagy T et al (2016) Recovery of glass fibre and carbon fibres from reinforced thermosets by batch pyrolysis and investigation of fibre re-using as reinforcement in LDPE matrix. Compos B Eng 91:154-161

62. Meyer LO, Schulte K, Grove-Nielsen E (2009) CFRP-recycling following a pyrolysis route: process optimization and potentials. J Compos Mater 43:1121-1132

63. Zhou Y, Qiu K (2010) A new technology for recycling materials from waste printed circuit boards. J Hazard Mater 175:823-828

64. Zhou Y, Wu W, Qiu K (2010) Recovery of materials from waste printed circuit boards by vacuum pyrolysis and vacuum centrifugal separation. Waste Manag 30:2299-2304

65. Onwudili JA, Insura N, Williams PT (2013) Autoclave pyrolysis of carbon reinforced composite plastic waste for carbon fibre and chemicals recovery. J Energy Inst 86:227-232

66. Shi J, Wada S, Kemmochi K, Bao L (2011) Development of recycling system for fiber-reinforced plastics by superheated steam. Key Engineering Materials, vol 464. Trans Tech Publications, Switzerland, pp 414-418. https://doi.org/10.4028/ www.scientific.net/KEM.464.414

67. Shi J, Kemmochi K, Bao L (2012) Research in recycling technology of fiber reinforced polymers for reduction of environmental load: optimum decomposition conditions of carbon fiber reinforced polymers in the purpose of fiber reuse. Advanced Materials Research, vols 343-344. Trans Tech Publications, Switzerland, pp 142-149. https://doi.org/10.4028/ www.scientific.net/AMR.343-344.142

68. Kim K-W, Lee H-M, An J-H et al (2017) Recycling and characterization of carbon fibers from carbon fiber reinforced epoxy matrix composites by a novel super-heated-steam method. J Environ Manag 203:872-879

69. Jeong J-S, Kim K-W, An K-H et al (2019) Fast recovery process of carbon fibers from waste carbon fibers-reinforced thermoset plastics. J Environ Manage 247:816-821 
70. Ye SY, Bounaceur A, Soudais Y et al (2013) Parameter optimization of the steam thermolysis: a process to recover carbon fibers from polymer-matrix composites. Waste Biomass Valorization 4:73-86

71. Kim K-W, Jeong J-S, An K-H et al (2019) A low energy recycling technique of carbon fibers-reinforced epoxy matrix composites. Ind Eng Chem Res 58:618-624

72. Obunai K, Fukuta T, Ozaki K (2015) Carbon fiber extraction from waste CFRP by microwave irradiation. Compos A Appl Sci Manuf 78:160-165

73. Jiang L, Ulven CA, Gutschmidt D et al (2015) Recycling carbon fiber composites using microwave irradiation: reinforcement study of the recycled fiber in new composites. J Appl Polym Sci. https://doi.org/10.1002/app.42658

74. Beauson J, Lilholt $\mathrm{H}$, Brøndsted P (2014) Recycling solid residues recovered from glass fibre-reinforced composites-a review applied to wind turbine blade materials. J Reinf Plast Compos 33:1542-1556

75. Pico D, Seide G, Gries T (2014) Thermo chemical processes: potential improvement of the wind blades life cycle. Chem Eng Trans 36:211-216

76. Åkesson D, Krishnamoorthi R, Foltynowicz Z et al (2013) Glass fibres recovered by microwave pyrolysis as a reinforcement for polypropylene. Polym Polym Compos 21:333-340

77. Åkesson D, Foltynowicz Z, Christéen J et al (2012) Microwave pyrolysis as a method of recycling glass fibre from used blades of wind turbines. J Reinf Plast Compos 31:1136-1142

78. Åkesson D, Foltynowicz Z, Christéen J et al (2013) Products obtained from decomposition of glass fiber-reinforced composites using microwave pyrolysis. Polimery 58:582-586

79. Jody BJ, Pomykala JA Jr, Daniels EJ et al (2004) A process to recover carbon fibers from polymer-matrix composites in endof-life vehicles. JOM 56:43-47

80. van de Werken N, Reese MS, Taha MR et al (2019) Investigating the effects of fiber surface treatment and alignment on mechanical properties of recycled carbon fiber composites. Compos A Appl Sci Manuf 119:38-47

81. Xiao B, Zaima T, Shindo K et al (2019) Characterization and elastic property modeling of discontinuous carbon fiber reinforced thermoplastics prepared by a carding and stretching system using treated carbon fibers. Compos Part A Appl Sci Manuf 126:105598. https://doi.org/10.1016/j.compositesa.2019.105598

82. Morin C, Loppinet-Serani A, Cansell F et al (2012) Near- and supercritical solvolysis of carbon fibre reinforced polymers (CFRPs) for recycling carbon fibers as a valuable resource: state of the art. J Supercrit Fluids 66:232-240

83. Liu Y, Meng L, Huang Y et al (2004) Recycling of carbon/epoxy composites. J Appl Polym Sci 94:1912-1916

84. Ma J, Wang X, Li B, et al (2009) Investigation on recycling technology of carbon fiber reinforced epoxy resin cured with amine. In: Advanced materials research, pp 409-412

85. Lee C-K, Kim Y-K, Pruitichaiwiboon P et al (2010) Assessing environmentally friendly recycling methods for composite bodies of railway rolling stock using life-cycle analysis. Transp Res Part D Transp Environ 15:197-203

86. Lee $\mathrm{S}-\mathrm{H}$, Choi H-O, Kim J-S et al (2011) Circulating flow reactor for recycling of carbon fiber from carbon fiber reinforced epoxy composite. Korean J Chem Eng 28:449-454

87. Yuyan L, Linghui $\mathrm{M}$, Yudong $\mathrm{H}$ et al (2006) Method of recovering the fibrous fraction of glass/epoxy composites. J Reinf Plast Compos 25:1525-1533

88. Dang W, Kubouchi M, Sembokuya $\mathrm{H}$ et al (2005) Chemical recycling of glass fiber reinforced epoxy resin cured with amine using nitric acid. Polymer 46:1905-1912

89. Li J, Xu P-L, Zhu Y-K et al (2012) A promising strategy for chemical recycling of carbon fiber/thermoset composites: self-accelerating decomposition in a mild oxidative system. Green Chem 14:3260-3263

90. Xu P, Li J, Ding J (2013) Chemical recycling of carbon fibre/ epoxy composites in a mixed solution of peroxide hydrogen and N,N-dimethylformamide. Compos Sci Technol 82:54-59

91. Das M, Chacko R, Varughese S (2018) An efficient method of recycling of CFRP waste using peracetic acid. ACS Sustain Chem Eng 6:1564-1571

92. Shin S-R, Mai VD, Lee D-S (2019) Chemical recycling of used printed circuit board scraps: recovery and utilization of organic products. Processes 7:22. https://doi.org/10.3390/pr7010022

93. Yousef S, Tatariants M, Tichonovas M et al (2018) Recycling of bare waste printed circuit boards as received using an organic solvent technique at a low temperature. J Clean Prod 187:780-788

94. Gao X, Li Q, Qiu J (2018) Hydrothermal modification and recycling of nonmetallic particles from waste print circuit boards. Waste Manag 74:427-434

95. Yang $P$, Zhou Q, Li X-Y et al (2014) Chemical recycling of fiberreinforced epoxy resin using a polyethylene glycol/ $\mathrm{NaOH}$ system. J Reinf Plast Compos 33:2106-2114

96. Yamaguchi A, Hashimoto T, Kakichi Y et al (2015) Recyclable carbon fiber-reinforced plastics (CFRP) containing degradable acetal linkages: synthesis, properties, and chemical recycling. J Polym Sci Part A: Polym Chem 53:1052-1059

97. Nie W, Liu J, Liu W et al (2015) Decomposition of waste carbon fiber reinforced epoxy resin composites in molten potassium hydroxide. Polym Degrad Stab 111:247-256

98. Wang Y, Cui X, Yang Q et al (2015) Chemical recycling of unsaturated polyester resin and its composites via selective cleavage of the ester bond. Green Chem 17:4527-4532

99. Wang Y, Cui X, Ge H et al (2015) Chemical recycling of carbon fiber reinforced epoxy resin composites via selective cleavage of the carbon-nitrogen bond. ACS Sustain Chem Eng 3:3332-3337

100. Liu T, Zhang M, Guo X et al (2017) Mild chemical recycling of aerospace fiber/epoxy composite wastes and utilization of the decomposed resin. Polym Degrad Stab 139:20-27

101. Oliveux G, Bailleul J-L, Gillet A et al (2017) Recovery and reuse of discontinuous carbon fibres by solvolysis: realignment and properties of remanufactured materials. Compos Sci Technol 139:99-108

102. Wu T, Zhang W, Jin X et al (2019) Efficient reclamation of carbon fibers from epoxy composite waste through catalytic pyrolysis in molten $\mathrm{ZnCl}_{2}$. $\mathrm{RSC}$ Adv 9:377-388

103. Ma Y, Kim D, Nutt SR (2017) Chemical treatment for dissolution of amine-cured epoxies at atmospheric pressure. Polym Degrad Stab 146:240-249

104. Ma Y, Nutt S (2018) Chemical treatment for recycling of amine/ epoxy composites at atmospheric pressure. Polym Degrad Stab 153:307-317

105. Jenkins PG (2017) Understanding physical changes and strength loss of E-glass fibres following exposure to elevated temperatures. Mater Sci Technol (UK) 33:255-264

106. Zhu P, Chen Y, Wang LY et al (2012) A new technology for separation and recovery of materials from waste printed circuit boards by dissolving bromine epoxy resins using ionic liquid. J Hazard Mater 239-240:270-278

107. Zhu P, Chen Y, Wang LY et al (2012) Treatment of waste printed circuit board by green solvent using ionic liquid. Waste Manag 32:1914-1918

108. Kamimura A, Yamamoto S, Yamada K (2011) Depolymerization of unsaturated polyesters and waste fiber-reinforced plastics by using ionic liquids: the use of microwaves to accelerate the reaction rate. ChemSusChem 4:644-649 
109. Sun H, Guo G, Memon SA et al (2015) Recycling of carbon fibers from carbon fiber reinforced polymer using electrochemical method. Compos A Appl Sci Manuf 78:10-17

110. Zhu J-H, Chen P-Y, Su M-N et al (2019) Recycling of carbon fibre reinforced plastics by electrically driven heterogeneous catalytic degradation of epoxy resin. Green Chem 21:1635-1647

111. Chen P-Y, Pei C, Zhu J-H et al (2019) Sustainable recycling of intact carbon fibres from end-of-service-life composites. Green Chem 21:4757-4768

112. Nzioka AM, Yan CZ, Kim M-G et al (2018) Improvement of the chemical recycling process of waste carbon fibre reinforced plastics using a mechanochemical process: influence of process parameters. Waste Manag Res 36:952-964

113. Das M, Varughese $S$ (2016) A novel sonochemical approach for enhanced recovery of carbon fiber from CFRP waste using mild acid-peroxide mixture. ACS Sustain Chem Eng 4:2080-2087

114. Jiang J, Deng G, Chen $X$ et al (2017) On the successful chemical recycling of carbon fiber/epoxy resin composites under the mild condition. Compos Sci Technol 151:243-251

115. Jiang G, Pickering SJ, Lester E, et al (2007) Recyling carbon fibre/epoxy resin composites using supercritical propanol. In: 16th international conference on composite materials

116. Marsh G (2009) Carbon recycling: a soluble problem. Reinf Plast 53:22-27

117. Piñero-Hernanz R, García-Serna J, Dodds C et al (2008) Chemical recycling of carbon fibre composites using alcohols under subcritical and supercritical conditions. J Supercrit Fluids 46:83-92

118. Okajima I, Hiramatsu M, Shimamura Y et al (2014) Chemical recycling of carbon fiber reinforced plastic using supercritical methanol. J Supercrit Fluids 91:68-76

119. Okajima I, Watanabe K, Haramiishi S et al (2017) Recycling of carbon fiber reinforced plastic containing amine-cured epoxy resin using supercritical and subcritical fluids. J Supercrit Fluids 119:44-5

120. Sokoli HU, Beauson J, Simonsen ME et al (2017) Optimized process for recovery of glass- and carbon fibers with retained mechanical properties by means of near- and supercritical fluids. J Supercrit Fluids 124:80-89

121. Okajima I, Sako T (2019) Recycling fiber-reinforced plastic using supercritical acetone. Polym Degrad Stab 163:1-6

122. Cheng $\mathrm{H}$, Huang $\mathrm{H}$, Zhang J et al (2017) Degradation of carbon fiber-reinforced polymer using supercritical fluids. Fibers Polym 18:795-805

123. Jiang G, Pickering S, Lester E et al (2009) Characterisation of carbon fibres recycled from carbon fibre/epoxy resin composites using supercritical n-propanol. Compos Sci Technol 69:192-198

124. Yan H, Lu C-X, Jing D-Q et al (2014) Chemical degradation of amine-cured DGEBA epoxy resin in supercritical 1-propanol for recycling carbon fiber from composites. Chin J Polym Sci (Engl Ed) 32:1550-1563

125. Yan H, Lu C-X, Jing D-Q et al (2016) Recycling of carbon fibers in epoxy resin composites using supercritical 1-propanol. Xinxing Tan Cailiao/New Carbon Mater 31:46-54

126. Piñero-Hernanz R, Dodds C, Hyde J et al (2008) Chemical recycling of carbon fibre reinforced composites in nearcritical and supercritical water. Compos A Appl Sci Manuf 39:454-461

127. Wang Y, Zhang S, Li G et al (2019) Effects of alkali-treated recycled carbon fiber on the strength and free drying shrinkage of cementitious mortar. J Clean Prod 228:1187-1195

128. Knight CC, Zeng C, Zhang C et al (2012) Recycling of woven carbon-fibre-reinforced polymer composites using supercritical water. Environ Technol 33:639-644

129. Yuyan L, Guohua S, Linghui M (2009) Recycling of carbon fibre reinforced composites using water in subcritical conditions. Mater Sci Eng A 520:179-183
130. Kim YN, Kim Y-O, Kim SY et al (2019) Application of supercritical water for green recycling of epoxy-based carbon fiber reinforced plastic. Compos Sci Technol 173:66-72

131. Bai $Y$, Wang Z, Feng $L$ (2010) Chemical recycling of carbon fibers reinforced epoxy resin composites in oxygen in supercritical water. Mater Des 31:999-1002

132. Okajima I, Hiramatsu M, Sako T (2011) Recycling of carbon fiber reinforced plastics using subcritical water. https://doi. org/10.4028/www.scientific.net/AMR.222.243

133. Keith MJ, Román-Ramírez LA, Leeke G et al (2019) Recycling a carbon fibre reinforced polymer with a supercritical acetone/ water solvent mixture: comprehensive analysis of reaction kinetics. Polym Degrad Stab 161:225-234

134. Yildirir E, Onwudili JA, Williams PT (2014) Recovery of carbon fibres and production of high quality fuel gas from the chemical recycling of carbon fibre reinforced plastic wastes. J Supercrit Fluids 92:107-114

135. Morales Ibarra R, Sasaki M, Goto M et al (2015) Carbon fiber recovery using water and benzyl alcohol in subcritical and supercritical conditions for chemical recycling of thermoset composite materials. J Mater Cycles Waste Manag 17:369-379

136. Keith MJ, Leeke GA, Khan P et al (2019) Catalytic degradation of a carbon fibre reinforced polymer for recycling applications. Polym Degrad Stab 166:188-201

137. Arturi KR, Sokoli HU, Søgaard EG et al (2018) Recovery of value-added chemicals by solvolysis of unsaturated polyester resin. J Clean Prod 170:131-136

138. Iwaya T, Tokuno S, Sasaki M et al (2008) Recycling of fiber reinforced plastics using depolymerization by solvothermal reaction with catalyst. J Mater Sci 43:2452-2456

139. Oliveux G, Bailleul J-L, Salle ELGL (2012) Chemical recycling of glass fibre reinforced composites using subcritical water. Compos A Appl Sci Manuf 43:1809-1818

140. Sanyal S, Ke Q, Zhang $Y$ et al (2013) Understanding and optimizing delamination/recycling of printed circuit boards using a supercritical carbon dioxide process. J Clean Prod 41:174-178

141. Oliveux G, Le Gal La Salle E, Bailleul J-L (2010) Recycling by solvolysis thermosetting composite materials of sustainable surface transport. In: AIP conference proceedings, pp 209-214

142. Oliveux G, Bailleul J-L, La Salle ELG et al (2013) Recycling of glass fibre reinforced composites using subcritical hydrolysis: reaction mechanisms and kinetics, influence of the chemical structure of the resin. Polym Degrad Stab 98:785-800

143. Gutiérrez E, Bono F (2013) Review of industrial manufacturing capacity for fibre-reinforced polymers as prospective structural components in Shipping Containers. JRC Sci Policy Rep 2-22, JRC77823, EUR 25719 EN, ISBN 97892-79-28120-4 (pdf), ISSN 1831-9424 (online). https://doi. org/10.2788/77853

144. Hermansson F, Janssen M, Svanström M (2019) Prospective study of lignin-based and recycled carbon fibers in composites through meta-analysis of life cycle assessments. J Clean Prod 223:946-956

145. Pillain B, Gemechu E, Sonnemann G (2017) Identification of key sustainability performance indicators and related assessment methods for the carbon fiber recycling sector. Ecol Ind 72:833-847

146. Dong PAV, Azzaro-Pantel C, Boix M et al (2017) A bicriteria optimisation approach for waste management of carbon fibre reinforced polymers used in aerospace applications: application to the case study of France. Waste Biomass Valorization $8: 2187-2208$ 
147. Howarth J, Mareddy SSR, Mativenga PT (2014) Energy intensity and environmental analysis of mechanical recycling of carbon fibre composite. J Clean Prod 81:46-50

148. La Rosa AD, Banatao DR, Pastine SJ et al (2016) Recycling treatment of carbon fibre/epoxy composites: materials recovery and characterization and environmental impacts through life cycle assessment. Compos B Eng 104:17-25

149. Khalil YF (2018) Comparative environmental and human health evaluations of thermolysis and solvolysis recycling technologies of carbon fiber reinforced polymer waste. Waste Manag 76:767-778

150. Khalil YF (2019) Sustainability assessment of solvolysis using supercritical fluids for carbon fiber reinforced polymers waste management. Sustain Prod Consum 17:74-84
151. Meng F, McKechnie J, Pickering SJ (2018) An assessment of financial viability of recycled carbon fibre in automotive applications. Compos A Appl Sci Manuf 109:207-220

152. Meng F, McKechnie J, Turner T et al (2017) Environmental aspects of use of recycled carbon fiber composites in automotive applications. Environ Sci Technol 51:12727-12736

153. Meng F, McKechnie J, Turner TA et al (2017) Energy and environmental assessment and reuse of fluidised bed recycled carbon fibres. Compos A Appl Sci Manuf 100:206-214

Publisher's Note Springer Nature remains neutral with regard to jurisdictional claims in published maps and institutional affiliations. 